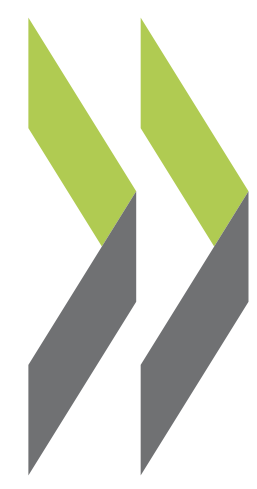

OECD Economics Department Working Papers No. 350

The US Health System: An Assessment and Prospective Directions for Reform
Elizabeth Docteur, Hannes Suppanz, Jaejoon Woo 
Organisation de Coopération et de Développement Economiques

Organisation for Economic Co-operation and Development

27-Feb-2003

ECONOMICS DEPARTMENT

English text only

THE US HEALTH SYSTEM: AN ASSESSMENT AND PROSPECTIVE DIRECTIONS FOR REFORM ECONOMICS DEPARTMENT WORKING PAPERS No. 350

by

Elizabeth Docteur, Hannes Suppanz and Jaejoon Woo

Most Economics Department Working Papers are now available through OECD's Internet Website at http://www.oecd.org/eco 


\section{ABSTRACT/RÉSUMÉ}

\section{The US health system: an assessment and prospective directions for reform}

This paper assesses the performance of the United States health system in an international context and discusses potential directions for reform. The US health system is unique among OECD countries in its heavy reliance on the private sector for both financing and delivery of health care. The public sector plays a not-insignificant role, providing coverage for the elderly, disabled and poor, and spending as much on health as a share of GDP as is spent in total by many OECD countries. The system is considered highly flexible, capable of evolving quickly to address the changing preferences of consumers and the incentives put in place by the requirements of payers and government regulation. It is also characterised by excellent access by the insured population to the latest advances in medical technology. However, 14 per cent of Americans lack insurance coverage, and the decentralised, multi-payer approach to financing and regulation provides relatively few levers to control spending. Instead, the system relies on competition among insurers and providers to increase efficiency. Although evidence is limited, it is not clear that the good clinical outcomes obtained are justified by the high relative spending levels, as other countries attain comparable outcomes for less. Systemic reforms, such as expansion of coverage and incentives to contain spending at the individual consumer level, could result in increased value for money.

JEL classification: I10, I11, I12, I18

Keywords: Healthcare, United States

\section{Le système de santé des États-Unis : évaluation et lignes directrices possibles pour une réforme}

Ce document évalue les performances du système de santé des États-Unis dans un contexte international et examine les directions potentielles pour une réforme. Le système de santé des États-Unis est sans équivalent dans la zone de l'OCDE, en ce sens qu'il dépend essentiellement du secteur privé à la fois pour le financement et la fourniture des soins de santé. Le secteur public joue un rôle non négligeable en procurant une couverture pour les personnes âgées, les handicapés et les pauvres et consacre autant pour la santé en part de PIB que ce que consacrent beaucoup de pays de la zone de l'OCDE pour l'ensemble des dépenses de santé. Le système est reconnu très souple, capable d'évoluer rapidement pour répondre aux changements dans les attentes des consommateurs, aux incitations mises en place par les exigences des payeurs et à la réglementation publique. Il est aussi caractérisé par un excellent accès aux dernières avancées technologiques en matière médicale pour la population assurée. Cependant 14 pour cent des américains ne sont pas couverts par une assurance et l'approche décentralisée, à organismes payeurs multiples pour le financement et la réglementation, limite les moyens d'action pour le contrôle des dépenses. Le système repose plutôt sur la concurrence entre les assureurs et les prestataires pour améliorer l'efficience. Il n'est pas clairement démontré que les bons résultats cliniques obtenus sont justifiés par des niveaux de dépenses relativement élevées, d'autres pays obtenant des résultats semblables pour moins cher. Des réformes du système, comme l'extension de la couverture et les incitations à contenir les dépenses au niveau du consommateur pourraient optimiser l'utilisation des fonds.

Classification JEL: I10, I11, I12, I18

Mots clés : Santé, États-Unis

Copyright $\odot$ OECD 2003. All rights reserved.

Applications for permission to reproduce or translate all, or part of, this material should be made to: Head of Publications Service, OECD, 2 rue André-Pascal, 75775 PARIS CEDEX 16, France 


\section{TABLE OF CONTENTS}

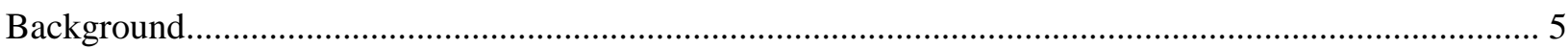

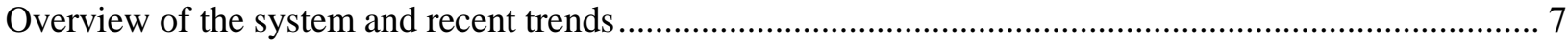

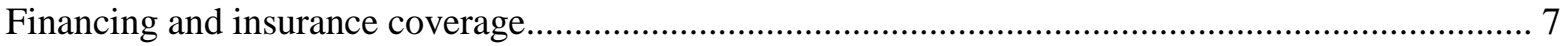

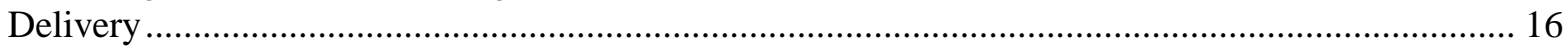

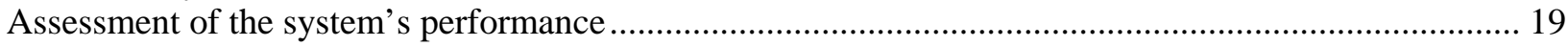

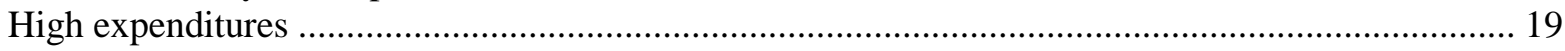

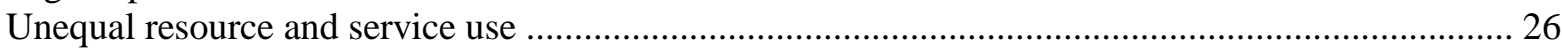

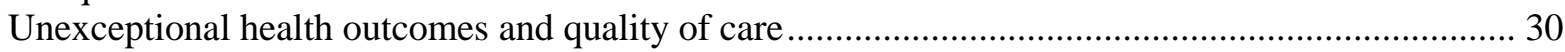

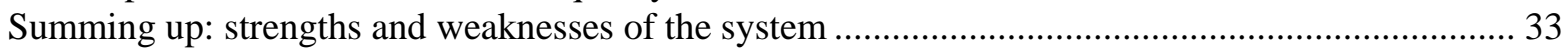

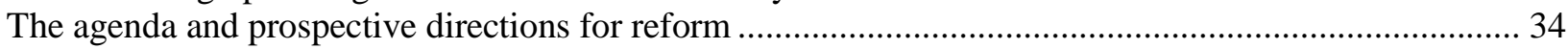

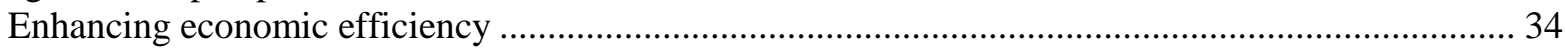

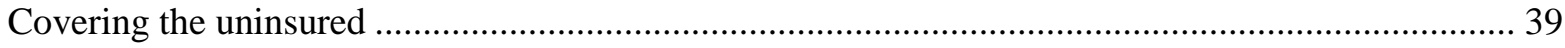

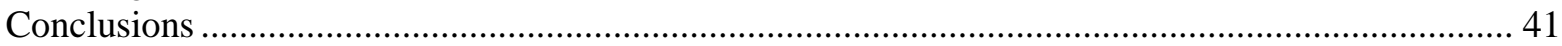

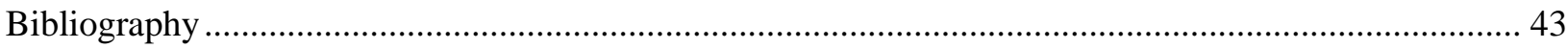

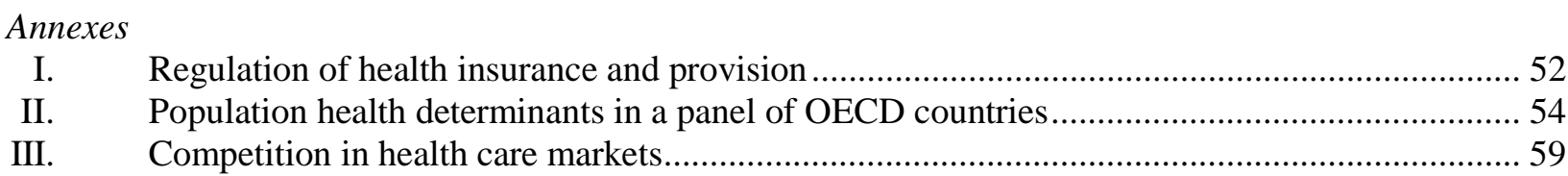

\section{Boxes}

1. Public and private sector roles in the US health system....................................................... 7

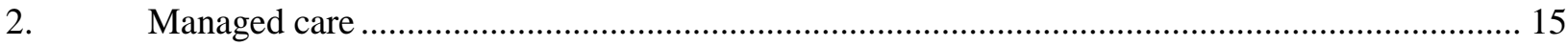

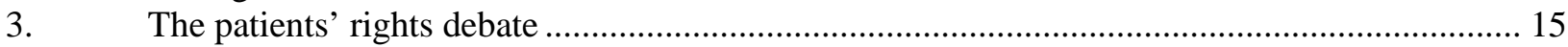

4. Prescription drug coverage for Medicare beneficiaries........................................................ 37

5. The Bush Administration's framework for Medicare reform ................................................... 38

6. Recommendations concerning the health care system .......................................................... 41

\section{Tables}

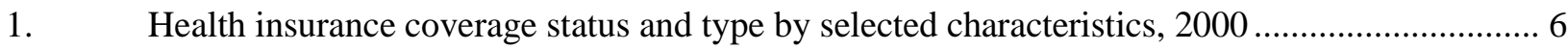

2. Personal health-care spending by source of funds ................................................................ 8

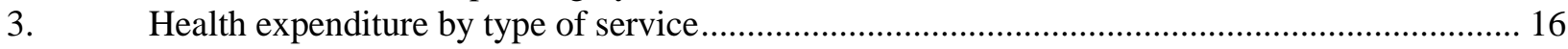

4. International comparison of health expenditure-related indicators ......................................... 24

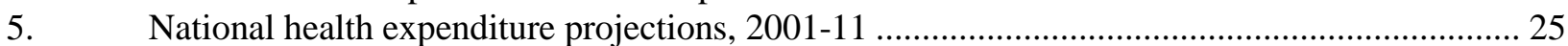

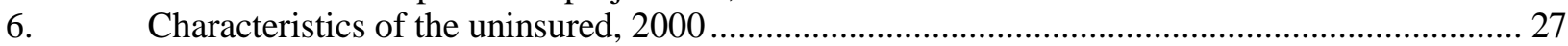

7. Tobacco consumption and nutrition among OECD countries................................................. 32

Annexes

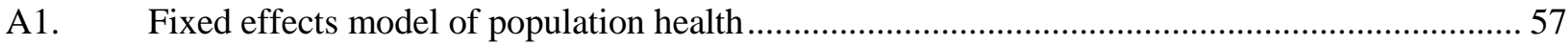

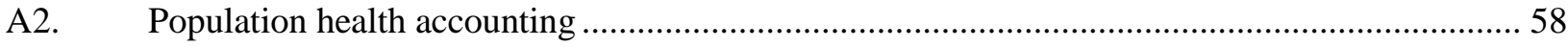




\section{Figures}

1. Tax expenditures from exclusion of employer contributions for health insurance premiums and

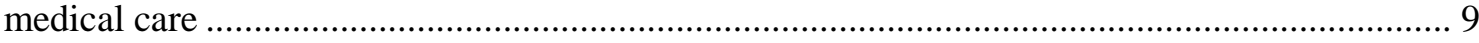

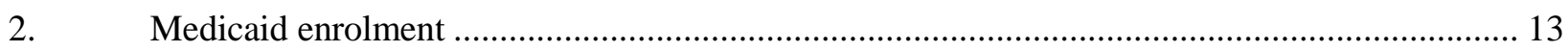

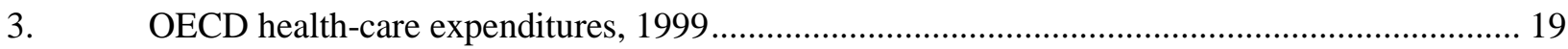

4. Health expenditure and GDP per capita, 1999 ….................................................................. 20

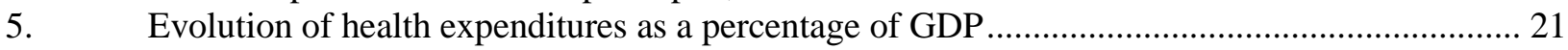

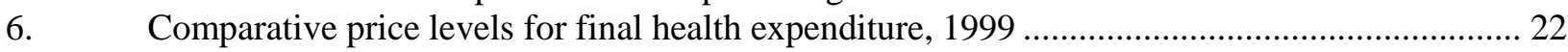

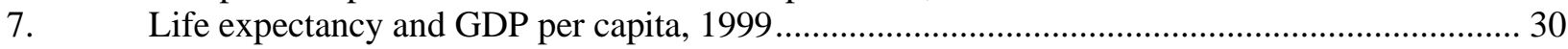


ECO/WKP(2003)4

\title{
THE US HEALTH SYSTEM: AN ASSESSMENT AND PROSPECTIVE DIRECTIONS FOR REFORM
}

\author{
Elizabeth Docteur, Hannes Suppanz and Jaejoon Woo'
}

\section{Background}

1. The US health care system is unique in the OECD area. The United States does not have a national insurance programme and 14 per cent of the population has no insurance coverage, although charity and subsidised programmes facilitate access to the medical system for the 40 million uninsured. It spends vastly more than other Member countries (14 per cent of GDP as compared with an OECD average of 8 per cent). It does relatively well in terms of clinical outcomes achieved. It is also responsive, adapting quickly to changes in consumer preferences, and the majority of Americans is highly satisfied with the care they receive. But, the costs of health care are high, and many Americans are at risk of being uninsured at some point in their lives. Also, like in other OECD countries, service use and health outcomes vary widely across the population. Neither public nor private payers have achieved much in the way of curbing expenditure growth over the long term, despite short-lived successes on the public side in containing prices through prospective payment systems and on the private side in controlling volume and costs through managed care. In addition, the system's performance on various measures of health status, in comparison with those of other OECD countries, calls into question the value of the high level of spending in terms of marginal improvements in population health, although arguably worse societal risk factors also play a role. Still, despite the remaining potential to achieve better value for money, improvements in population health seem to have yielded substantial increases in national income (Nordhaus, 2002).

2. The crosscutting issues of incomplete insurance coverage, escalating costs and seemingly inefficient spending were highlighted in an earlier OECD review of the US health care system (OECD, 1992). But they continue to present fundamental challenges to US policymakers. And with a surge in health spending not seen since the 1980s and a recent economic downturn that is expected to have left an increasing number of people uninsured, health care reform is high on the policy agenda. Because of the system's diversity, decentralisation and private nature, fewer policy levers exist at the national level to address these problems than in many other OECD countries. Therefore, reforms have tended to proceed incrementally and on a piecemeal basis, state by state and programme by programme. The private sector is a critical force driving change in both delivery and funding of health care.

1. The authors are members of the OECD Secretariat. This paper was originally produced for the $O E C D$ Economic Survey of the United States published in November 2002 under the authority of the Economic and Development Review Committee. The authors are indebted to Peter Jarrett, Peter Scherer, Michael Feiner, Jorgen Elmeskov, Val Koromzay, Antonio Giuffrida, Manfred Huber, Jeremy Hurst, Stephane Jacobzone, Howard Oxley and Nicole Tapay for comments and drafting suggestions, and to the US authorities for their assistance with obtaining the information and clarifications necessary to prepare the paper. Special thanks go to Françoise Correia for invaluable technical assistance with the graphs and to Mee-Lan Frank for expert word processing. 
3. The purpose of this paper is to reassess the opportunities and challenges in the US health system. It begins by providing an overview of its characteristics, focussing on recent trends. It continues with an assessment of its performance, first by analysing expenditures, use of resources and services, and health outcomes, and then evaluating how their determinants represent strengths and weaknesses. Finally, the paper reviews prospective directions for reforming components of the health system to address underlying problems and provides some recommendations for change.

Table 1. Health insurance coverage status and type by selected characteristics, 2000 Per cent ${ }^{1}$

\begin{tabular}{|c|c|c|c|c|c|c|c|c|}
\hline & \multicolumn{7}{|c|}{ Covered by private or government insurance } & \multirow{3}{*}{$\begin{array}{c}\text { Not covered } \\
\text { Uninsured } \\
\end{array}$} \\
\hline & \multirow[b]{2}{*}{ Total } & \multicolumn{2}{|c|}{ Private insurance } & \multicolumn{4}{|c|}{ Government health insurance } & \\
\hline & & Total & $\begin{array}{c}\text { Employment } \\
\text { based }\end{array}$ & Total & Medicaid & Medicare & Military & \\
\hline \multicolumn{9}{|l|}{ People } \\
\hline Total & 86.0 & 72.4 & 64.1 & 24.2 & 10.4 & 13.4 & 3.0 & 14.0 \\
\hline \multicolumn{9}{|l|}{ Sex } \\
\hline Male & 85.1 & 72.8 & 65.3 & 22.2 & 9.4 & 12.0 & 3.3 & 14.9 \\
\hline Female & 86.9 & 72.0 & 62.9 & 26.1 & 11.3 & 14.7 & 2.8 & 13.1 \\
\hline \multicolumn{9}{|l|}{ Race and ethnicity } \\
\hline White & 87.1 & 75.0 & 65.9 & 23.3 & 8.6 & 14.2 & 2.9 & 12.9 \\
\hline Non-Hispanic & 90.3 & 79.4 & 69.5 & 23.2 & 7.0 & 15.4 & 3.1 & 9.7 \\
\hline Black & 81.5 & 58.9 & 54.4 & 31 & 20.3 & 10.6 & 3.8 & 18.5 \\
\hline Asian and Pacific Islander & 82.0 & 69.9 & 62.9 & 18.3 & 11.3 & 7.5 & 2.6 & 18.0 \\
\hline Hispanic (Hispanics can be of any race) & 68.0 & 47.9 & 44.6 & 24.3 & 18.6 & 6.5 & 1.6 & 32.0 \\
\hline \multicolumn{9}{|l|}{ Age } \\
\hline Under 18 years & 88.4 & 70.5 & 66.2 & 23.3 & 20.4 & 0.7 & 2.9 & 11.6 \\
\hline 18 to 24 years & 72.7 & 64.8 & 53.4 & 11.9 & 8.7 & 0.6 & 2.9 & 27.3 \\
\hline 25 to 34 years & 78.8 & 72.1 & 68.1 & 9.0 & 6.3 & 1.1 & 2.2 & 21.2 \\
\hline 35 to 44 years & 84.5 & 78.6 & 74.3 & 8.7 & 5.4 & 1.8 & 2.6 & 15.5 \\
\hline 45 to 64 years & 87.4 & 79.4 & 72.6 & 12.5 & 5.6 & 5.5 & 3.3 & 12.6 \\
\hline 65 years and over & 99.3 & 61.5 & 33.8 & 96.6 & 10.0 & 96.2 & 4.2 & 0.7 \\
\hline \multicolumn{9}{|l|}{ Nativity } \\
\hline Native & 88.1 & 74.5 & 65.9 & 24.8 & 10.4 & 13.7 & 3.2 & 11.9 \\
\hline Foreign born & 68.4 & 54.9 & 48.7 & 19.3 & 9.9 & 11.1 & 1.5 & 31.6 \\
\hline Naturalized citizen & 84.1 & 66.8 & 58.1 & 27.7 & 9.4 & 21.4 & 2.4 & 15.9 \\
\hline Not a citizen & 58.7 & 47.6 & 43.0 & 14.1 & 10.2 & 4.8 & 0.9 & 41.3 \\
\hline \multicolumn{9}{|l|}{ Region } \\
\hline Northeast & 88.6 & 75.1 & 67.2 & 24.8 & 11.6 & 14.2 & 1.6 & 11.4 \\
\hline Midwest & 89.2 & 78.7 & 69.5 & 21.6 & 8.4 & 13.2 & 1.9 & 10.8 \\
\hline South & 84.2 & 69.6 & 61.7 & 25.4 & 10.0 & 14.3 & 4.1 & 15.8 \\
\hline West & 83.3 & 68.2 & 59.9 & 24.5 & 11.9 & 11.5 & 3.5 & 16.7 \\
\hline \multicolumn{9}{|l|}{ Household income } \\
\hline Less than $\$ 25000$ & 77.3 & 41.2 & 27.6 & 52.4 & 27.7 & 28.7 & 2.6 & 22.7 \\
\hline$\$ 25000$ to $\$ 49999$ & 83.0 & 70.2 & 60.9 & 25.7 & 9.8 & 14.7 & 3.5 & 17.0 \\
\hline$\$ 50000$ to $\$ 74999$ & 89.0 & 83.3 & 77.4 & 13.5 & 4.3 & 7.1 & 3.2 & 11.0 \\
\hline$\$ 75000$ or more & 93.1 & 90.1 & 84.9 & 9.3 & 2.2 & 5.2 & 2.7 & 6.9 \\
\hline \multicolumn{9}{|l|}{ Education (18 years and older) } \\
\hline Total & 85.2 & 73.1 & 63.3 & 24.5 & 6.8 & 17.9 & 3.0 & 14.8 \\
\hline No high school diploma & 73.4 & 45.8 & 35.7 & 43.1 & 16.5 & 32.6 & 2.0 & 26.6 \\
\hline High school graduate only & 83.6 & 71.0 & 60.9 & 27.0 & 7.2 & 19.8 & 3.1 & 16.4 \\
\hline Some college no degree & 86.6 & 77.6 & 66.4 & 19.7 & 4.8 & 13.0 & 4.0 & 13.4 \\
\hline Associate degree & 89.7 & 82.5 & 74.5 & 17.2 & 3.7 & 11.0 & 4.2 & 10.3 \\
\hline Bachelor's degree or higher & 92.9 & 88.1 & 79.8 & 14.5 & 2.0 & 11.2 & 2.6 & 7.1 \\
\hline \multicolumn{9}{|l|}{ Work experience (18 to 64 years old) } \\
\hline Total & 82.4 & 75.3 & 69.0 & 10.6 & 6.2 & 2.8 & 2.8 & 17.6 \\
\hline Worked during year & 83.8 & 80.3 & 74.6 & 6.2 .0 & 3.3 & 0.6 & 2.6 & 16.2 \\
\hline Worked full-time & 84.6 & 82.0 & 77.4 & 5.2 .0 & 2.5 & 0.4 & 2.5 & 15.4 \\
\hline Worked part-time & 79.3 & 71.6 & 60.0 & 11.2 & 7.3 & 1.6 & 3.0 & 20.7 \\
\hline Did not work & 76.4 & 52.4 & 43.6 & 31.0 & 19.5 & 13.0 & 4.0 & 23.6 \\
\hline
\end{tabular}

1. Percentages may not add up to totals because some people hold multiple forms of coverage.

Source: US Census Bureau, Current Population Survey, March 2001. 


\section{Overview of the system and recent trends}

4. Both the public and the private sectors play critical roles in the US health system (Box 1). The private sector is dominant in terms of providing insurance coverage for most Americans, but the public sector plays a significant role in financing. The largest federal programme, Medicare, is the dominant purchaser in many markets and serves as a model for other payers in terms of payment formulas. Most delivery is privately administered. ${ }^{2}$ Regulation of the sector is a shared responsibility between the state and federal governments, the boundaries of which are not always clear (Annex I).

\section{Box 1. Public and private sector roles in the US health system}

Federal government. One of the most prominent roles of the federal government in health care is as a purchaser of health insurance and third-party payer for health care. The federal government serves in this capacity for 39 million elderly and disabled persons, 9 million federal government employees and their dependants, and 6 million active members of the military and their families. It finances, in conjunction with the states, state-run insurance programmes for the poor and near-poor children. It runs a health care delivery system designed to serve military veterans. In addition, the federal government influences the health system by serving as a primary locus for collecting health data and the principal source of funding for health services research. Notably absent is a national health planning function, although various federal agencies track health system characteristics, trends and aspects of performance.

State governments. Responsibility for regulating health care providers and insurance companies is the prerogative of the individual states. Another critical role they play is in the management and financing (together with the federal government) of public programmes to provide health insurance or direct health care to poor children and families. They also purchase health insurance on behalf of state government employees, thus influencing the local markets for insurance products. There is significant variation in how active states are in their regulatory, management and purchasing activities.

Local (city/county/parish) governments. Local governments, in conjunction with states, play an important role in financing the so-called safety net providers (e.g. county hospitals) that serve the indigent. They also maintain emergency response service systems.

Private sector. Most health care facilities are privately owned and operated. Hospitals and other institutions can be run either not-for-profit or for-profit. Similarly, health insurance plans are private. Most operate for profit, with the significant exception of most Blue Cross/Blue Shield plans. Some serve as contractors to Medicare, being responsible for administrative functions such as making payments to health care providers and practitioners.

\section{Financing and insurance coverage}

5. Health care financing and insurance coverage is atypical of OECD countries in that it reflects multiple payers and sources of coverage that vary depending on population characteristics such as employment, income and age (Table 1). Most of the working-age population and their dependants are covered by employer-provided insurance plans. Medicare, a social insurance programme, covers virtually all senior citizens and some of the disabled. Medicaid and the State Children's Health Insurance Program (SCHIP) serve as a social assistance safety net, covering the poorest and those whose medical expenses consume a large portion of their income, along with near-poor children (up to a family income level set by the state). However, gaps in eligibility for public programmes, inability or unwillingness to purchase private insurance (in part because of the availability of public programmes and free care) and other barriers to enrolment leave a significant and increasing percentage of the population without any form of health

2. An exception is the Veterans' Administration health system, an integrated system of health care financing and delivery for benefit of the nation's military retirees. 
insurance coverage (14 per cent in 2000). In addition, some people are underinsured, leaving their health and finances at risk (Short and Banthin, 1995).

\section{Purchasers/payers}

Private insurance

6. Nearly three-quarters of the US population are covered by private health insurance, which accounts for a rising share of total spending on health (over a third by 2000, Table 2). Most private insurance policies are purchased by employers in either the small-group or the large-group market, which provides the greatest pooling of risk. Many large employers are self-insured. Employers are not required by law to offer coverage to their employees, but tax considerations encourage them to do so. ${ }^{3}$ The value of the premium is excluded from the calculation of employees' taxable earnings, nor do they or their employers pay payroll taxes on such compensation. Currently amounting to about 1 per cent of GDP, these tax exclusions represent a significant source of foregone federal revenue (Figure 1).

Table 2. Personal health-care spending by source of funds

Per cent

\begin{tabular}{|c|c|c|c|c|c|c|}
\hline & 1960 & 1970 & 1980 & 1990 & 1995 & 2000 \\
\hline Private funds & 78.6 & 64.8 & 59.7 & 61.0 & 55.4 & 56.7 \\
\hline Out-of-pocket payments & 55.2 & 39.7 & 27.1 & 22.5 & 16.9 & 17.2 \\
\hline Private insurance & 21.4 & 22.3 & 28.3 & 33.4 & 33.4 & 34.6 \\
\hline Other & 2.0 & 2.8 & 4.3 & 5.0 & 5.1 & 5.0 \\
\hline Public funds & 21.4 & 35.2 & 40.3 & 39.0 & 44.6 & 43.3 \\
\hline Federal funds & 8.7 & 22.9 & 29.3 & 28.6 & 34.1 & 32.8 \\
\hline Medicare & 0.0 & 11.5 & 16.9 & 17.6 & 20.6 & 19.2 \\
\hline Medicaid $^{1}$ & 0.0 & 4.3 & 6.4 & 6.6 & 9.5 & 9.8 \\
\hline Other & 8.7 & 7.1 & 6.0 & 4.4 & 4.0 & 3.8 \\
\hline State and local funds & 12.6 & 12.3 & 11.1 & 10.5 & 10.5 & 10.5 \\
\hline Medicaid $^{1}$ & 0.0 & 3.7 & 5.1 & 4.8 & 6.2 & 6.9 \\
\hline Other & 12.6 & 8.6 & 5.9 & 5.6 & 4.3 & 3.6 \\
\hline
\end{tabular}

1. Including SCHIP.

Source: Centers for Medicare and Medicaid Services (CMS).

7. Following a period of relatively slow growth, premiums for employer-sponsored insurance rose by 11 per cent in 2001. Since then their growth has accelerated further, approaching the increases of 15 to 20 per cent common in the 1980s. Such growth is partly a predictable consequence of the health insurance underwriting cycle and partly a reflection of growth in underlying costs, such as prescription drugs (Gabel et al., 2001). Nonetheless, both the share of employers offering coverage and the share of the premium borne by employees has remained relatively stable, reflecting the tight employment market at the onset of the economic downturn and the size of the tax incentive. Last year, employees contributed an

3. In practice, nearly all firms with 200 or more workers offer health insurance, as do 65 per cent of employers with between 3 and 199 employees (Gabel et al., 2001). Firms that employ many low-wage workers are least likely to offer insurance, as are companies with high employee turnover. Some workers are not covered because their employer does not offer coverage. Others are not eligible to enrol because of waiting periods or minimum standards for hours worked. Still others choose not to enrol because of the amount of the contribution the employee is required to make or because they have coverage available through another source. 
average of 15 per cent of the cost of a policy covering an individual and 27 per cent of the cost of family coverage (Gabel et al., 2001). The $\$ 30$ employees paid on average per month for single coverage in 2001 was less in nominal dollars than in 1993, near the bottom of the previous business cycle. However, during the past two years, employers have reduced prescription drug benefits and increased co-payments and deductibles more generally in order to shift costs to users (Trude et al., 2002). Many employers have also reduced the benefits in the insurance policies that they offer to their retirees. ${ }^{4}$

\section{Figure 1. Tax expenditures from exclusion of employer contributions for health insurance premiums and medical care}

\section{$\$$ billions}

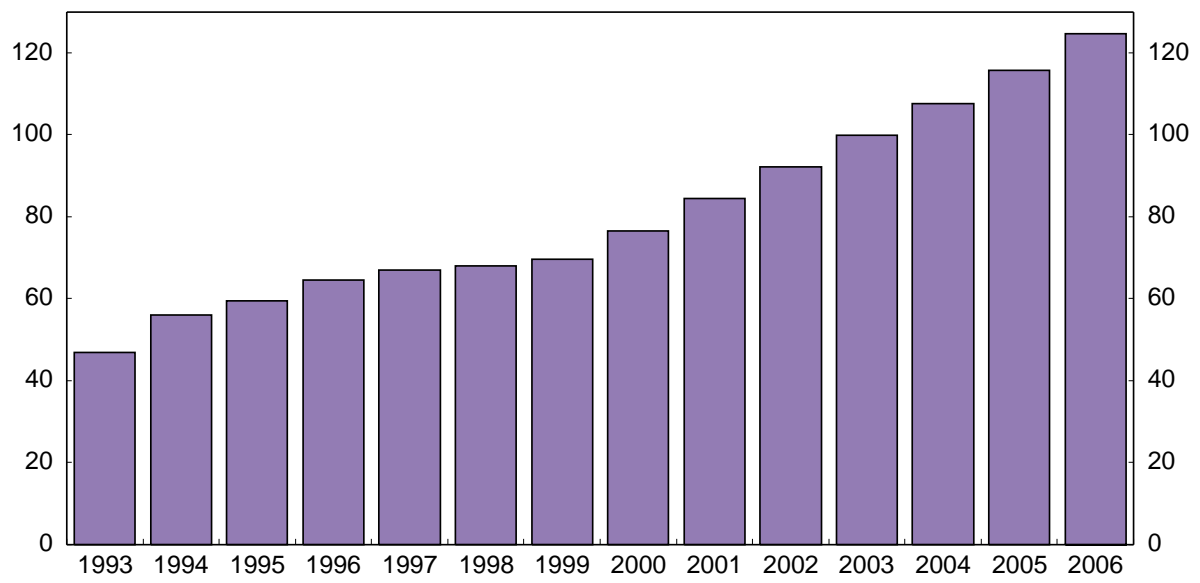

Source: Federal Budget, Analytical Perspectives, various issues (1995-2002).

8. As compared with the share covered by employer-sponsored health insurance, a relatively small percentage of the population is covered by insurance purchased directly in the commercial non-group market. ${ }^{5}$ This market is characterised by higher administrative overhead associated with writing policies on an individual basis. From the perspective of those who are sick, uninsured, and seeking to buy coverage, individually purchased insurance tends to be neither attractive nor accessible in that premiums can be risk-adjusted for individual characteristics in most states, and the policies often exclude coverage for pre-existing conditions and carry high deductibles. As a result, coverage for those with health problems is considerably more costly than in the group market (Gabel, 2002), although some suggest there is not a large difference (Pauly and Herring, 2001 and Council of Economic Advisors, 2002). Some states and communities administer programmes designed to make coverage more affordable for individuals and employers in the small-group market. Some offer community-rated pricing, under which premiums are not subject to medical underwriting. This is an approach that seeks to minimise the extent to which premiums vary according to current and prospective health status and related factors (such as age) and that is likely to

4. Since 1993 the percentage of employers offering health benefits to retirees under the age of 65 has dropped from 46 to 31 per cent, while the percentage of employers offering coverage designed to supplement Medicare for eligible retirees has fallen from 40 to 24 per cent (Fronstin, 2001a). It should be mentioned, however, that there is coverage available for purchase under COBRA provisions and HIPAA protection for people leaving employer coverage (including retirees).

5. In 2000, 7 per cent of Americans under age 65 held an individually purchased health insurance policy (Fronstin, 2001b). Although about one-third of Medicare beneficiaries have an individually purchased, private supplemental (Medigap) policy, this market is heavily regulated, and its problems are not the same as those in the standard non-group commercial market for health insurance. 
result in higher costs for the younger and healthier in the near term. Others have publicly subsidised premiums. Still others have established high-risk pools for the otherwise hard-to-insure. ${ }^{6}$ These have been, at best, a mixed success, because the cost of even subsidised premiums still puts insurance out of the reach of many would-be purchasers. In addition to these programmes, a federal income tax deduction for the cost of health insurance premiums paid by the self-employed is being phased in (in 2003, 100 per cent of the premium cost will be deductible, up from 25 per cent in 1986 when the deduction was established).

\section{Public programmes}

9. Virtually all Americans aged 65 or older are covered by Medicare, as are qualified disabled persons (after a two-year waiting period). It accounts for one-fifth of total health spending and is financed through a combination of a payroll tax levied on workers and their employers, and premium payments by beneficiaries. ${ }^{7}$ Under the traditional programme, which covered 86 per cent of Medicare beneficiaries in 2001, payments to hospitals, physicians and other providers are determined by complex prospective payment systems. ${ }^{8,9}$ These systems provide the programme with a high level of control over the price component of total spending, but not much leverage over the volume of services. The remaining beneficiaries are enrolled in the Medicare+Choice programme, under which private health plans are paid a monthly capitation payment for each enrolee that is based on the amount Medicare spends per beneficiary in the geographic area served by the plan. Under this system, the total payment by Medicare to plans is fixed, and each health plan establishes its own methods for administering benefits and paying providers within parameters established by federal regulation. Medicare's traditional programme does not cover outpatient prescription drugs and many preventive services (such as routine physical examinations), and its cost-sharing arrangements include annual deductibles, co-payments and a cap on benefits that puts beneficiaries at risk for the costs of long hospital stays. Medicare+Choice plans are required to offer a benefits package that is at least as generous from an actuarial standpoint as the traditional programme's; in practice, most participating health plans offer a more generous package as a means of attracting enrolees. Most of those enrolled in the traditional programme have some form of supplemental insurance that covers some or all of the cost-sharing and that fills in gaps in the benefits package (Medicare Payment Advisory

6. All states are required by law to have coverage arrangements for individuals who are hard to insure in the individual market. About 30 states have high-risk pools.

7. Employers and workers each pay half of a mandatory payroll tax of 2.9 per cent to fund the hospital insurance (Part A) component of Medicare, which furnishes insurance for inpatient hospital care and health care in skilled nursing facilities and some other institutions. Those entitled to Part A are also eligible to enrol in Part B, which offers coverage for physicians' services, laboratory work and other medical supplies and services at the cost of a subsidised monthly premium. General tax revenues finance 75 per cent of the cost of Medicare Part B; the other quarter is financed through premium revenues.

8. Prospective payment systems establish levels of payment (which may be based, in whole or in part, on an estimate of resource requirements) in advance of the provision of services, as opposed to cost-based payment systems, which determine payments retrospectively as a function of actual costs incurred. Prospective payment systems may establish rates per service, provide a bundled payment for a group of services, or set rates based on another unit, such as per diem, per discharge or per episode of treatment.

9. In traditional Medicare, most hospital inpatient services are paid according to a system of diagnosis-related groups (DRGs), which establishes national rates per discharge based on the diagnosis and type of service furnished. Adjustments to hospital payments take into account higher input prices in urban areas, the provision of graduate medical education and charity care. Physicians' fees for each covered service are set according to a relative value scale, which was developed and is updated in consultation with medical experts, and conversion factors that adjust for various components of practice expense. 
Commission, 2000). ${ }^{10}$ The prevalence of such coverage limits beneficiary cost sensitivity and tends to increase use of services through moral hazard effects (Christensen and Shinogle, 1997).

10. The Medicare+Choice programme was created as part of the Balanced Budget Act (BBA) of 1997, building on the foundation of an existing programme under which some private health plans participated in Medicare under either a risk or cost-reimbursement basis. ${ }^{11}$ A new programme to educate beneficiaries about their enrolment choices and to disseminate comparative information on health care quality and other dimensions of health plan performance was also implemented in an effort to help beneficiaries make value-based decisions. In practice, however, Medicare+Choice has failed to attract significant new participation by private health plans in Medicare (Gold, 2001). In fact, many plans have withdrawn from the programme or restricted their service areas since the programme began. ${ }^{12}$ Participating plans have also reduced benefits (including prescription drug coverage) or increased cost sharing. In a period when private health plans are again experiencing rapidly rising costs, Medicare payment rates may be too low in many localities to allow plans to offer benefits packages that will attract and retain enrolees. ${ }^{13}$ Also, new regulatory requirements, including ones that require plans to furnish information on quality of care and other dimensions of performance, have added to plans' costs of participating in Medicare.

11. In addition to creating Medicare+Choice, the BBA of 1997 made other significant changes to Medicare that have had ongoing effects on both the programme and the health system as a whole. Notably, the legislation made significant reductions in the annual payment increases to hospitals that had larger fiscal effects than initially projected, slowing the rate of growth in hospital spending until subsequent legislation increased payment levels. Furthermore, the legislation established prospective payment systems for post-acute care, including home health care and skilled nursing facility care, components of Medicare spending that had grown rapidly since the introduction of prospective payment for hospitals established incentives for early discharge of patients. A result of the changes in Medicare and the rapidity with which they were implemented was an outcry on the part of providers and health plans objecting to the burden of complying with Medicare's increasingly numerous, changeable and complicated regulatory requirements.

12. Medicaid and the State Children's Health Insurance Program (SCHIP) cover essentially poor families with children, low-income elderly and the disabled. ${ }^{14}$ The total cost of these schemes has approached that of Medicare. The federal government and individual states jointly fund Medicaid under a system whereby state outlays are matched at a rate determined by the income levels of each state's

10. The primary forms of supplemental insurance coverage are employer-sponsored plans for retirees and individually purchased "Medigap" policies, each of which cover about a third of Medicare beneficiaries, and Medicaid, which provides supplemental coverage for about 15 per cent of beneficiaries.

11. Prior to the Medicare+Choice programme, only health maintenance organisations could participate in Medicare. Now preferred provider organisations and other types of managed care plans, as well as privately administered fee-for-service plans and medical savings accounts are also eligible.

12. In the first three years of Medicare+Choice, health plan withdrawals and service area contractions affected 1.7 million beneficiaries who had to change plans or switch to the traditional programme. Total beneficiary enrolment in private health plans peaked at 6.3 million at end-1999. Within two years that had fallen to about 5.5 million, the same as in 1997.

13. Updates to payment levels, which are set in statute, have not kept pace with health-care cost increases in some areas.

14. Under federal law, state Medicaid programmes must cover certain groups and are permitted to expand coverage to other designated groups such as all children 18 and under who live in families with incomes below 100 per cent of the federal poverty level. They are permitted, but not required, to cover pregnant women and infants under age 1 whose family income is between 133 and 185 per cent of that level. 
residents. ${ }^{15}$ Each state designs and administers its own programme, within federal parameters, resulting in significant variation in coverage, benefits and payments. This variation has also permitted states to develop and test a variety of approaches to coverage. Although children and adults in low-income families constitute three-quarters of Medicaid's enrolment, spending is heavily concentrated on the programme's elderly and disabled enrolees. In addition to its coverage of acute care and preventive services, Medicaid is the single largest payer for long-term care, which is not covered by Medicare and most private health insurance plans. ${ }^{16}$ Over the course of the past decade, most states have contracted with private managed care plans to serve beneficiaries formerly covered under traditional fee-for-service arrangements. More than half of programme beneficiaries, predominantly poor children and their parents, obtained care through such plans as of 1999 (Kaiser Commission on Medicaid and the Uninsured, 2001a). Subsequent to federal authorisation in the BBA of 1997, states began to enrol their disabled beneficiaries in managed care plans as well. Employing such arrangements for elderly Medicaid beneficiaries, most of whom are dually enrolled in Medicare and Medicaid, has not yet been undertaken in many states, however. ${ }^{17}$

13. SCHIP was also created as part of the $1997 \mathrm{BBA}$ in an effort to expand coverage of uninsured children. Under this programme, states obtain federal funding at a higher matching rate than is provided under Medicaid for children in families with incomes up to (and in some cases above) 200 per cent of the federal poverty level. ${ }^{18}$ Although more than three-quarters of all uninsured children are eligible for public insurance coverage under Medicaid or SCHIP, many eligible children have yet to be enrolled (Kenney and Haley, 2001), despite considerable progress recently. ${ }^{19}$ A relatively low rate of participation is characteristic of other social assistance programmes as well.

14. Medicaid enrolment grew by almost half in the first half of the 1990s (Figure 2), reflecting the sluggish economy and increased coverage. It then declined somewhat as the economy surged, unemployment fell and significant changes in welfare policy at the federal level affected eligibility. ${ }^{20}$ State budget surpluses encouraged renewed programme expansion beginning in 1999, but this is now posing problems as the less robust economy and escalating health care costs once again challenge state budgets, most of which - unlike the federal budget - must be balanced annually. In response, states have undertaken a number of strategies to address shortfalls (e.g. cutting provider payments and enrolment eligibility). Enrolment is estimated to have exceeded mid-1990s levels last year, and experts expect significant further stress on state Medicaid programmes concentrated in long-term care for the elderly and disabled (Kaiser Commission on Medicaid and the Uninsured, 2001b).

15. The federal government's cost share ranges from 50 to 83 per cent. With limited exceptions, it also pays half states' administrative costs for Medicaid. At nearly 60 per cent, the average federal contribution has changed little over the past decade.

16. Reliance on social assistance programmes to finance long-term care is not unusual among OECD countries.

17. For those who are dually enrolled in Medicare and Medicaid, Medicare serves as the primary payer, while Medicaid covers cost sharing, deductibles and payment for care not covered in the Medicare benefits package, such as prescription drugs and long-term care. States' ability to mandate managed care enrolment for dual enrolees is limited by federal provisions allowing Medicare beneficiaries to have unrestricted choice among health care providers.

18. Most states have chosen to furnish SCHIP coverage by expanding Medicaid eligibility, although others are creating new programmes or subsidising private coverage.

19. SCHIP enrolment increased from 2.7 million in December 2000 to 3.5 million in December 2001, according to estimates of the Kaiser Commission on Medicaid and the Uninsured.

20. However, since the federal welfare reforms were implemented in 1996-97, Medicaid eligibility no longer coincides with eligibility for receipt of cash assistance. 
Figure 2. Medicaid enrolment

Millions

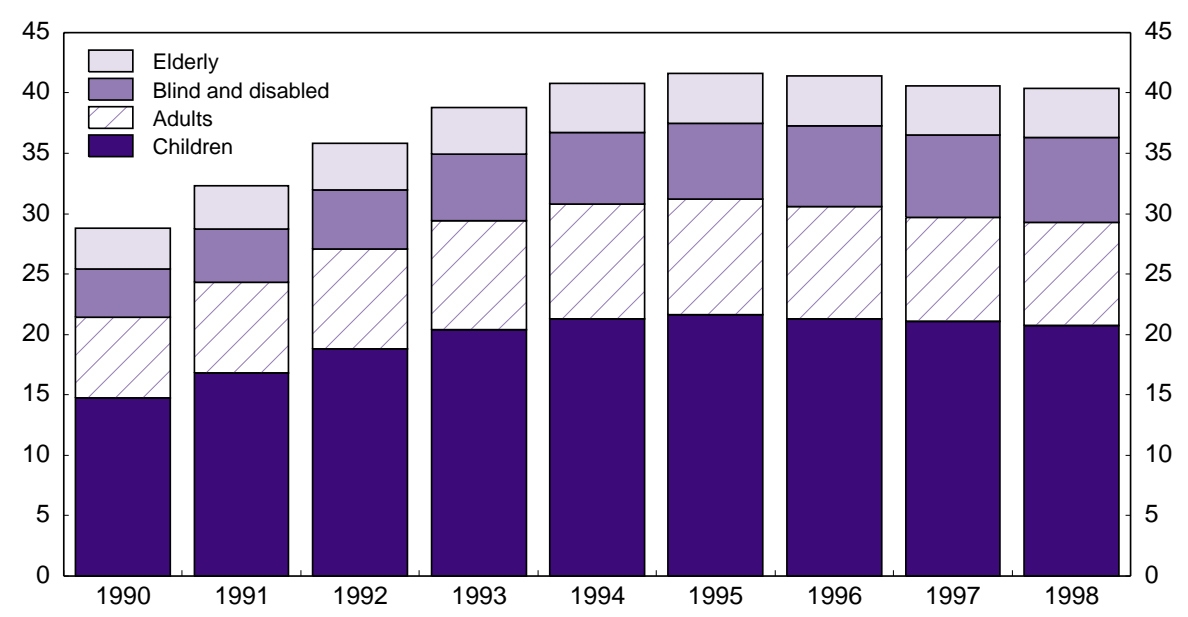

Source: Urban Institute.

Out-of-pocket spending by individuals

15. After trending downwards until the mid-1990s, the share of individual out-of-pocket spending has stabilised at about one-sixth of total health expenditure, which is close to the OECD average. Such spending includes costs associated with the use of health care services, including deductibles, co-payments (cost sharing that represents a fixed amount per service), coinsurance (cost sharing that represents a fixed percentage of payment) and payments for services not covered by insurance. Across the population, there is wide variation in the amount of out-of-pocket spending, depending on the source of coverage, type of insurance and amount of service use. For example, while average out-of-pocket spending among Medicare beneficiaries averaged one-fifth of income in 1997, for those below the poverty level without assistance from Medicaid it reached, on average, about half of income (Gross et al., 1999). Those who spend a relatively high proportion (at least 7.5 per cent) of their income on out-of-pocket costs for health care may deduct the excess from their federal income tax base. Also, many employers offer flexible spending accounts that allow for pre-tax payment of out-of-pocket spending. ${ }^{21}$

\section{Means of financing care for the uninsured}

16. Those who lack insurance nonetheless do obtain care, the costs of which must be borne by the health system. The burden of financing care for the uninsured differs significantly across geographic areas and presents variable amounts of stress on public and private sources of funding. Some of the costs of care for the uninsured are covered by patients and their families. Absent the discounted rates often negotiated by third-party payers, the uninsured may be charged higher prices for services, although some providers are willing to accept lower fees from those with low incomes. One recent study found that the chronically

21. As the use of flexible spending accounts has been limited by the "use it or lose it" (at the end of the year) requirement, the Treasury has very recently announced a new programme to address this issue. Under the Health Reimbursement Arrangement programme, employers of any size can set up a pre-tax employee benefit that can be used to pay out-of-pocket expenses and unused balances from one year can be used for spending in subsequent years. 
ill uninsured had higher out-of-pocket spending than their insured counterparts, on average, despite being five times less likely to see a physician (Hwang et al., 2001). The American Hospital Association and the American Medical Association estimate that charity care provided by hospitals and physicians is approximately $\$ 56$ billion per year, or more than $1 / 2$ per cent of GDP. Public hospitals and health clinics receive special funding to support care for those who lack insurance and cannot afford to pay for care out of pocket. Teaching and community hospitals and individual physicians in private practice also provide safety-net services. Billions in such care is reimbursed by public programmes, which, for example, make payment adjustments to those hospitals that serve a disproportionate share of indigent patients. Uncompensated care is also indirectly supported by public programmes designed to promote provision of care in under-served areas, including assistance to providers with loan repayment, payment bonuses for physicians and programmes that facilitate care by non-physician practitioners. Other such care effectively represents charitable provision and seems to have been adversely affected by increased price competition associated with the spread of managed care (Cunningham et al., 1999).

\section{Health insurance and health plans}

17. Some payers, such as Medicare under its traditional programme, directly purchase health care from providers who deliver it to programme enrolees. Others, such as most employers and the Medicare+Choice programme, buy insurance, passing to private health plans the financial risk of furnishing covered benefits to enrolees. Large private employers often self-fund to save on the costs of insurance and administration and gain more freedom in benefits management (as they can exempt themselves from state mandates that affect only insured plans). Whether self-funded or insured, most buyers contract with health plans to administer enrolee benefits and payments to providers. Most, but not all, types of health plans also undertake some degree of management of health care delivery.

\section{Evolution of insurance arrangements}

18. The past decade has seen very great changes in the nature of US health insurance arrangements. Up until the early 1990s, traditional indemnity, fee-for-service insurance coverage was predominant. The shift is still ongoing with only 7 per cent of workers having such coverage in 2001, down from 27 per cent in 1996 (Gabel et al., 2001). Such coverage is characterised by the ability of enrolees to see any provider willing to accept the service-specific rates offered by the insurer. The fee-for-service plan may undertake utilisation review to determine whether a service is part of a covered benefit but does not take other steps to manage or co-ordinate care. This type of coverage has all but disappeared everywhere except in Medicare, although some forms of managed care (Box 2) tend to be discounted fee-for-service with large networks and limited health care management, blurring the line between types of coverage.

19. Most of the 1990s represented a period of rapid expansion in managed care. This was particularly true in the private sector, where employers embraced it as an opportunity to gain control over the sharply increasing costs of furnishing health benefits. The same strategies (i.e. limits on patient choice of provider and treatment, intervention in physician practice decisions and selective contracting with alternative providers and suppliers) that led to dramatic cost savings for payers tended to alienate both health care providers and patients, however, resulting in a backlash against managed care's most restrictive characteristics. The ensuing political pressure led to a wave of state legislation in the mid-1990s to require coverage of particular services, establish minimum hospital stays for certain conditions, set forth practitioner rights and address other concerns. Discomfort at the political level with the nature and scope of health plan involvement in what were essentially medical decisions led to efforts to develop a framework 


\section{Box 2. Managed care}

Managed (or co-ordinated) care is a generic term for health plans that take active steps to affect the type or amount of care their enrolees receive. Managed care plans differ from traditional indemnity plans primarily in that they have detailed contractual or employment relationships with health care providers. On one end of the spectrum, plans require enrolees to choose a primary care physician who, in exchange for a fixed monthly payment, furnishes primary care and directs the referral of patients to specialists. The physician or a group of physicians may share with the health plan the resulting financial risk. On the less managed end of the spectrum, some plans allow beneficiaries to use services from any provider within the network and pay providers on a discounted fee-for-service basis.

Approaches for controlling costs used by managed care plans include requiring pre-authorisation for services, particularly specialist visits and hospitalisations, and selective contracting with providers who are willing to accept the plan's payment arrangements. Managed care plans have a designated network of participating providers, although some cover care by non-network providers at a higher cost under what is known as a point-of-service (POS) option. Plan networks may be relatively small, as in the case of health maintenance organisations (HMOs) known as staff-model HMOs, in which physicians are employed by the plan. In the case of many preferred provider organisations (PPOs), in which the plan contracts with providers who generally participate in more than one plan, networks tend to be larger and patients are frequently not required to obtain authorisation from a gatekeeper prior to obtaining services. Under PPO arrangements, physicians are also often paid on a discounted fee-for-service basis.

Most recent studies have found evidence that managed care arrangements — particularly HMOs — can result in reduced health care costs, at least in the short term, owing to "payer-driven" competition resulting from the shift of purchasing power toward well-informed and price-sensitive insurers and employers. Their premium growth has been significantly slower than in traditional insurance (Luft and Miller, 1997). Also, their presence is associated with reduced cost growth in the area in most recent studies (Glied, 2000). For example, one study of California hospitals found that, between 1983 and 1993, hospital expenditures grew 44 per cent less rapidly in markets with high HMO penetration than in those with low penetration (Robinson, 1996). Another (Baker et al., 2000) found that total costs for employer health plans are about 10 per cent lower in markets that have HMO market share above 45 per cent than they are in markets with HMO enrolments of below 25 per cent. Some studies have also documented a spillover effect in which markets with high managed care penetration rates have lower rates of cost growth even under indemnity coverage.

for patient-plan relations that was embodied in various proposals, known as a patients' bill of rights (see, for example, President's Advisory Commission on Consumer Protection and Quality in the Health Care Industry, 1997; Box 3). Various versions of these protections have since been adopted in requirements established by public programmes, employers, individual health plans and states via legislation.

\section{Box 3. The patients' rights debate}

The expansion of managed care and its administrative restrictions on patients and providers resulted in great dissatisfaction and a backlash, as well as a concern about the effect on quality of care. This has now largely been dispelled by a move away from such tight plan management. However, the notion of patients' rights persists as a politically popular cause. Congress has debated national legislation to establish certain patients' rights. Because numerous states have passed patients' rights laws and many purchasers, including the federal government, have imposed them on the health plans with which they do business, some provisions of the Congressional proposals currently being considered are effectively in place for many individuals with insurance coverage. However, the outstanding issue that has deadlocked Congress is disagreement about the extent of damages the patient can receive if a plan wrongfully denies coverage. The debate centres on the impact of such expansion on healthcare costs, including the costs associated with new liabilities for employers, and the potential for related insurance coverage losses.

20. Insurance companies responded to consumer demand and new requirements by creating products characterised by fewer administrative controls, larger networks and more out-of-network coverage (Draper et al., 2002). Preferred provider organisations (PPOs) now enrol 48 per cent of workers, up from 
28 per cent in 1996, and point-of-service plans, which allow out-of-network care under different cost-sharing arrangements, increased their share from 14 to 22 per cent over the same period (Gabel et al., 2001). Such plans have replaced HMOs as the predominant form of coverage. In addition, plans known as provider service organisations (PSOs), essentially provider coalitions that take on health plan functions, emerged as part of a physician-led effort to regain control over health care practices. ${ }^{22}$ These changes in managed care have significant implications, both in terms of the projected rate of private health spending growth and of the potential for health plans to play the lead role in a system of value-based competition as envisaged by some proponents of systemic reform.

\section{Delivery}

21. Hospital care, physician services and prescription drugs together constitute the bulk of spending on health care (Table 3). The major development over the 1990s has been the shift from hospital to drug expenditure, with the shares of physician services and other components remaining relatively stable. It is noteworthy, however, that, despite the strong rise in prescription drug spending, its share is still relatively low by international comparison (see below).

Table 3. Health expenditure by type of service

Percentage of total health care spending

\begin{tabular}{|c|c|c|c|c|c|c|}
\hline & 1960 & 1970 & 1980 & 1990 & 1995 & 2000 \\
\hline Personal health care & 87.6 & 86.5 & 87.3 & 87.6 & 87.4 & 87.0 \\
\hline Hospital care & 34.4 & 37.8 & 41.3 & 36.5 & 34.7 & 31.7 \\
\hline Physician and clinical services & 20.1 & 19.1 & 19.2 & 22.6 & 22.3 & 22.0 \\
\hline Dental services & 7.4 & 6.4 & 5.4 & 4.5 & 4.5 & 4.6 \\
\hline Other professional services & 1.5 & 1.0 & 1.5 & 2.6 & 2.9 & 3.0 \\
\hline Home health care & 0.2 & 0.3 & 1.0 & 1.8 & 3.1 & 2.5 \\
\hline Other non-durable medical products & 6.1 & 4.6 & 4.0 & 3.2 & 2.6 & 2.4 \\
\hline Prescription drugs & 10.0 & 7.5 & 4.9 & 5.8 & 6.1 & 9.4 \\
\hline Durable medical equipment & 2.4 & 2.3 & 1.6 & 1.5 & 1.4 & 1.4 \\
\hline Nursing home care & 3.2 & 5.8 & 7.2 & 7.6 & 7.5 & 7.1 \\
\hline Other personal care & 2.4 & 1.7 & 1.3 & 1.4 & 2.3 & 2.8 \\
\hline Non-personal health care & 12.4 & 13.5 & 12.7 & 12.4 & 12.6 & 13.0 \\
\hline $\begin{array}{l}\text { Administration and net cost of private } \\
\text { health insurance }\end{array}$ & 4.5 & 3.8 & 4.9 & 5.7 & 6.1 & 6.2 \\
\hline Public health activity & 1.5 & 1.9 & 2.7 & 2.9 & 3.2 & 3.4 \\
\hline Research & 2.6 & 2.7 & 2.2 & 1.8 & 1.7 & 2.0 \\
\hline Construction & 3.8 & 5.2 & 2.8 & 2.0 & 1.6 & 1.4 \\
\hline
\end{tabular}

Source: Centers for Medicare and Medicaid Services (CMS).

\section{Providers and suppliers}

22. The health care delivery system has been in a period of considerable flux. The key players have had to adapt to the evolving landscape presented by changes in financing, service organisation and delivery and medical practice as reflected in the rise, and more recent fall, of managed care. One important result has been the development of more formal and informal relationships across providers of one type and

22. Recent innovations like Health Reimbursement Arrangements may spur future evolution of the market toward personal care arrangements of a defined contribution type. 
among providers of different types. Mergers, vertical integration, network development and moves to unionise hospital-based physicians are all aspects of this trend.

Hospitals

23. The number of hospitals has fallen by 14 per cent over the past decade. Most are community hospitals, two-thirds of which are private, not-for-profit institutions, while the remainder are investor-owned or public establishments. ${ }^{23}$ In addition, some hospitals are run by the federal government for the benefit of military personnel, veterans, native Americans or others. The decline in the number of hospitals has been accompanied by a significant reduction in the number of inpatient beds per capita. The ratio of inpatient beds per 1000 persons fell from 4.9 in 1990 to 3.6 in 2000, one of the lowest among OECD countries.

24. These changes reflect a number of factors. First, both the spread of managed care in the private sector and Medicare's prospective payment system have created incentives to reduce the length of hospital stays. Second, cost containment efforts by managed care plans have resulted in mergers designed to increase hospitals' market power and reduce overhead expenses. Reinforced by developments in the science of medicine and patient preferences, these factors have combined to move more care that would formerly have been provided in hospitals on an inpatient basis into less intensive institutional settings and ambulatory care environments. ${ }^{24}$ It is unclear whether this trend will be cost saving. Hospitals have not been passive bystanders to these events. Rather, they have been active players in the ongoing move toward integration, in which health care providers of various types develop business relationships with others designed to assist them in competing with other networks for business contracts. Such relationships include hospitals purchasing physician practices and home health agencies, as well as merging with competitors. Hospitals have done so under antitrust, anti-kickback and other regulatory constraints.

\section{Physicians}

25. The United States has about three physicians for every 1000 residents, a rate comparable to that found in the median OECD country. About one-third of US doctors are primary care physicians, and the remainder are specialists. Physician payment methods vary widely by payer and type of practice from fee for service to capitation. Payment arrangements of all types sometimes include special incentive payments designed to reward cost-conscious referral patterns or, still more rarely, superior performance on measures of health care quality or patient satisfaction. Some hospital-based physicians, such as radiologists, may be salaried employees of the hospital, who may also receive a share of fee-for-service billing revenues. Both the Medicare and Medicaid programmes, which provide more than a quarter of physician payments, have schedules of fixed reimbursement prices.

26. The patient/physician relationship is in a period of change at present, reflecting both a broad movement toward active consumerism and the rapid decline in information asymmetry in health care, through the Internet, in particular. Physicians increasingly experience patients who expect to be active decision makers in their care. In the same vein, work has been undertaken to develop and test interactive

23. Community hospitals are accessible by the general public and include short-term general hospitals and special hospitals focusing on obstetrics and gynaecology, rehabilitation care or other selected services.

24. Prospective payment systems for care provided in settings that can substitute for some inpatient care, such as outpatient departments, have only recently been developed and implemented by Medicare and other payers. Formerly, Medicare's payments to these providers were calculated on the basis of incurred costs. 
tools to assist patients in assessing alternative treatment options for some conditions. Early evaluations of these tools suggest that fully informed patients are inclined to choose less invasive or aggressive procedures, on average, than less informed patients acting on their physician's advice.

Post-acute/sub-acute care providers and long-term care

27. Health care needs that do not require the level of medical intensity provided in an inpatient hospital stay are met through the post-acute and sub-acute care sectors, while related needs that are not strictly medical in nature are furnished through the long-term care sector. The overlap ${ }^{25}$ between these kinds of care presents a number of challenges for health policy, particularly in the Medicare programme, which provides coverage for post-acute care, but not for long-term care (which is covered by Medicaid). Other countries face similar challenges in meeting the health care and other needs of their elderly and disabled populations; however, co-ordinating two separate public programmes designed to meet a closely related group of needs for vulnerable populations is a characteristic unique to the US system. The post-acute care sector has grown rapidly since incentives to release inpatient hospital patients as soon as feasible took effect in the mid-1980s. Home health care tripled its share of personal health expenditures between 1980 and 1995, as hospital lengths of stay fell. The BBA of 1997 authorised the establishment of new prospective payment systems in Medicare; these have subsequently been implemented for home health agencies and skilled nursing facilities (hospital-based and free-standing). As a result, costs in this sector first declined and have now resumed relatively slow growth (Levit et al., 2002).

\section{Prescription drugs}

28. Although prescription drugs are a smaller component of spending than elsewhere, ${ }^{26}$ pharmaceuticals have represented the most rapidly growing cost component of the health care delivery system since 1980 (Table 3). Price developments are only partly responsible for these increases. A high proportion is the result of new drugs and increased utilisation, as illustrated by an increase in the annual number of retail prescriptions per person from 8.3 in 1995 to 10.5 in 2000 (Levitt et al., 2002). This growth reflects the development of new medications to address health problems, the preference for treating problems using drugs versus other methods of treatment, and newly permissible direct advertising to consumers $^{27}$ that spurs demand. Better coverage and therefore less price sensitivity also plays a role: most private health plans and Medicaid (but not Medicare) provide coverage. In 2000, 68 per cent of the costs of prescription drugs were met by insurance, as opposed to only 41 per cent in 1990 (Levitt et al., 2002).

25. In practice, there is considerable overlap along the continuum of needs. Home care agencies supply both home health care and other types of personal assistance on a short- and long-term basis. Nursing homes and some hospitals offer skilled nursing care, while rehabilitation hospitals and rehabilitation departments of acute care hospitals furnish sub-acute rehabilitation care.

26. In 2000, the United States spent around 10 per cent of its total health expenditures on pharmaceuticals, as compared with an OECD average of about 15 per cent and a range of 9 to 25 per cent. As a share of GDP, this represents $13 / 4$ per cent compared with an OECD average of $1 \frac{1}{4}$ per cent.

27. Spending on direct advertising to consumers nearly tripled from 1997 to 2000 , reaching $\$ 2.3$ billion. 
Figure 3. OECD health-care expenditures, $1999^{1}$ As per cent of GDP

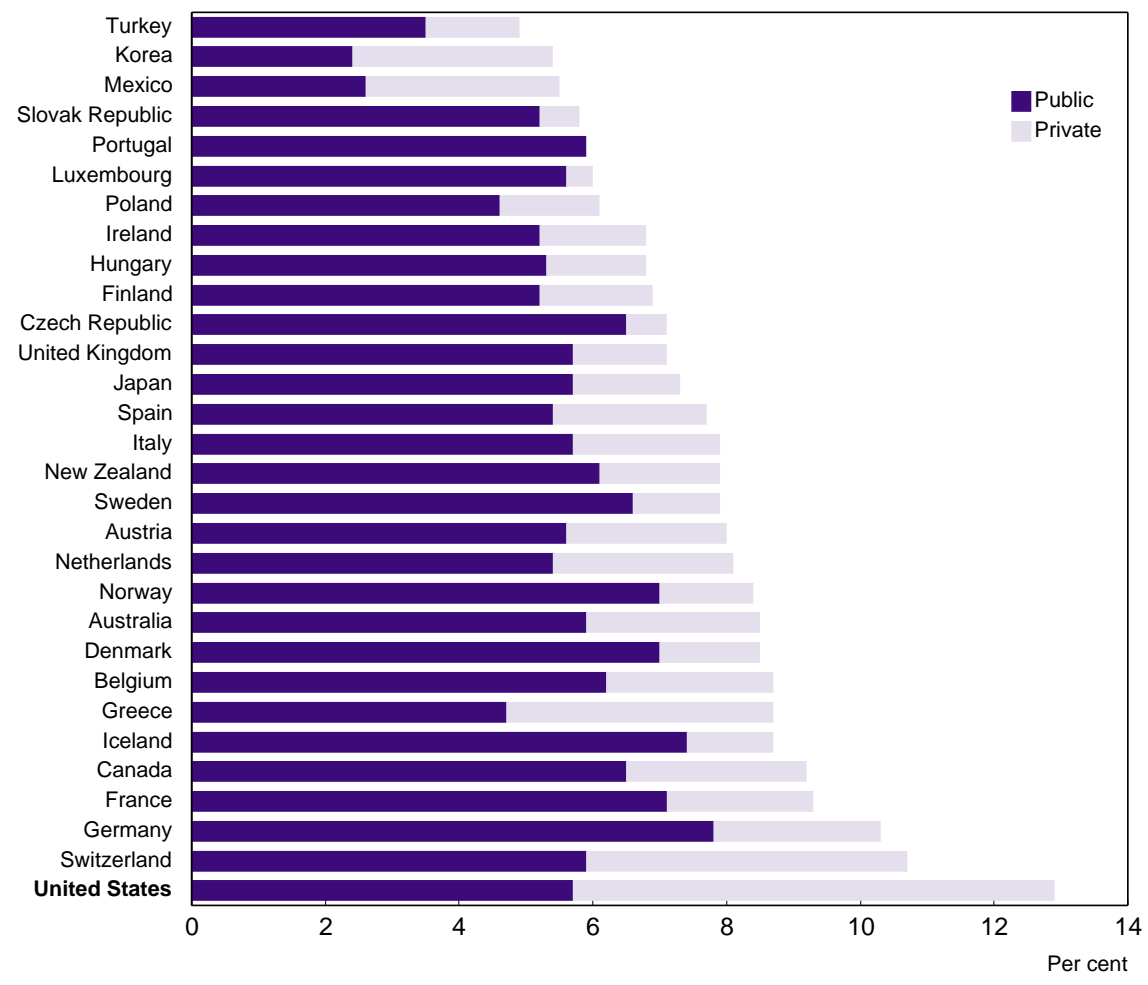

1998 for Australia, Germany, Sweden and Turkey.

Source: OECD Health Data, 2002.

\section{Assessment of the system's performance}

29. A striking feature of the US health system is high spending in comparison with that of other OECD countries, even taking account of relative income levels (Figures 3 and 4). ${ }^{28}$ On other dimensions of performance, outcomes reflect the substantial amount of diversity within the system. There are substantial gaps in access to care and wide variation in resource and service use that is not necessarily correlated with differences in medical needs. In some areas, the quality-adjusted price of care has probably fallen, but the country's relative performance in others suggests that the marginal increase in health status, if any, is very costly.

\section{High expenditures}

\section{Salient features}

30. In 2000, OECD figures showed total spending on health represented about 13 per cent of gross domestic product, as compared to an estimated average for all OECD countries of about 8 per cent. The next highest spending nations, Switzerland and Germany, just exceeded the mark of 10 per cent of GDP. In

28. The data in the Figures refer to 1999 because more recent data are not yet available for all countries. 
Figure 4. Health expenditure and GDP per capita, $1999^{1}$

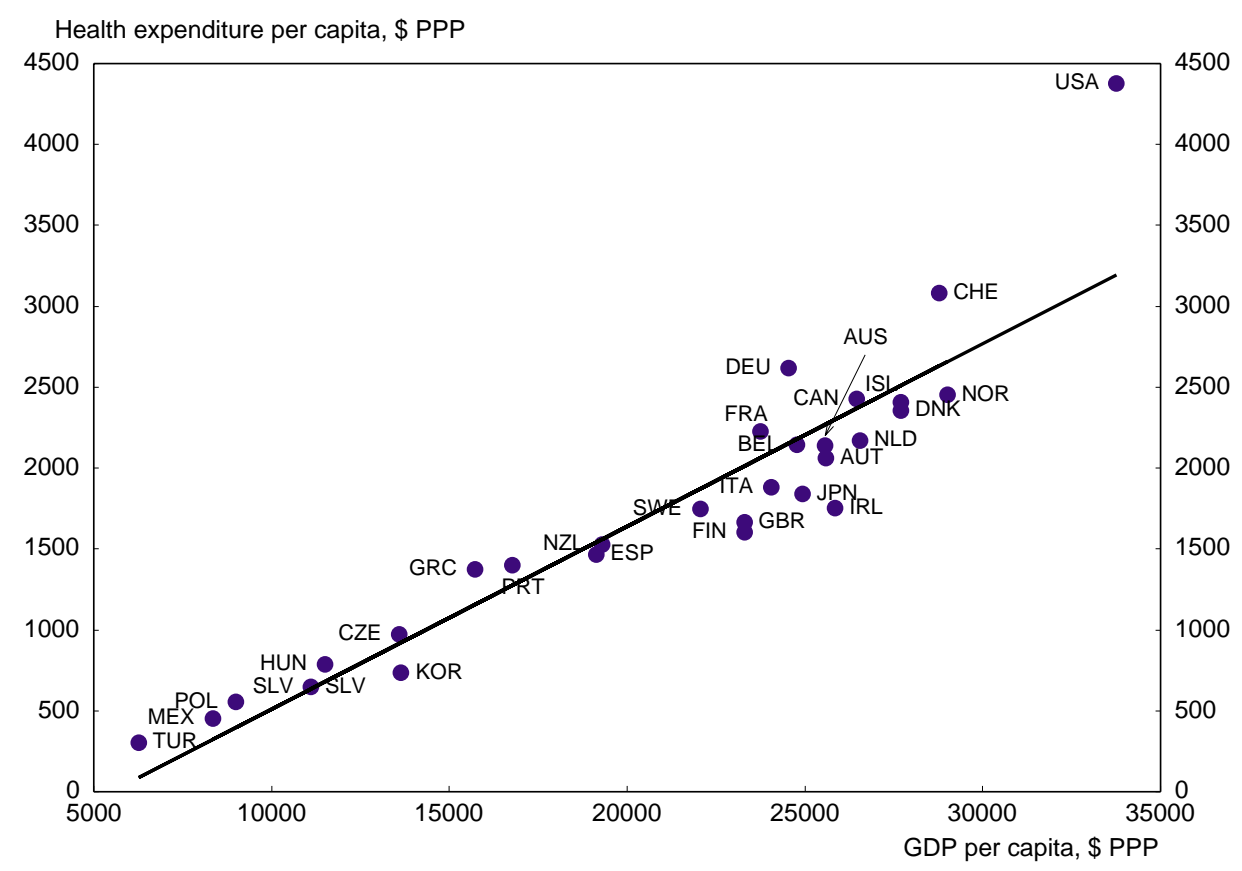

Note: The regression line is: Health expenditure per capita $=-615+0.1128$ * GDP per capita

R squared $=.86$

$(-3.2) \quad(12.9)$

1998 for Sweden and Turkey.

Source: OECD.

terms of per capita spending (based on purchasing power parities), the United States leads by a large margin. With an average of $\$ 4631$ per person spent on health in 2000, the nation spent more than two and one-half times the OECD average. Furthermore, there is a noticeable relationship between income levels in a country and health expenditure per capita, but the United States is a significant outlier - spending far more on health than this relationship would indicate. US health spending has been consistently higher than that of other countries since tracking began in 1960, predating the creation of Medicare and Medicaid, but the gap to the OECD average widened markedly during the 1980s and early 1990s (Figure 5). Thereafter, as generally abroad, spending stabilised relative to GDP so that the gap remained broadly unchanged. However, at the end of the decade, growth in health expenditure began to outpace income again, reaching 14 per cent of GDP in 2001, according to official estimates.

31. Because public spending constitutes less than half of total expenditure on health care in the United States and because it is spread across a range of programmes, the federal government has less direct control over total health spending than governments in other OECD countries. ${ }^{29}$ On average in the OECD countries, public spending comprises three-quarters of the total, and only one other country, Korea, funds less than half of its health expenditures through the public sector. It is worth noting, however, that direct public spending as a share of GDP in the United States (at just below 6 per cent) is close to the OECD average (Figure 3), and tax exclusions in the United States provide substantial additional support to private health insurance (Figure 1). Altogether, public support in relation to GDP is thus probably at least as high as anywhere in the OECD (Woolhandler and Himmelstein, 2002). It should also be borne in mind that compulsory social insurance contributions paid by employers in other countries are counted as public

29. In 2000, 70 (31) per cent of public (total) spending was made by the federal government. 
expenditure, while premiums paid voluntarily by employers for health insurance coverage in the United States are classified as private spending.

\section{Figure 5. Evolution of health expenditures as a percentage of GDP}

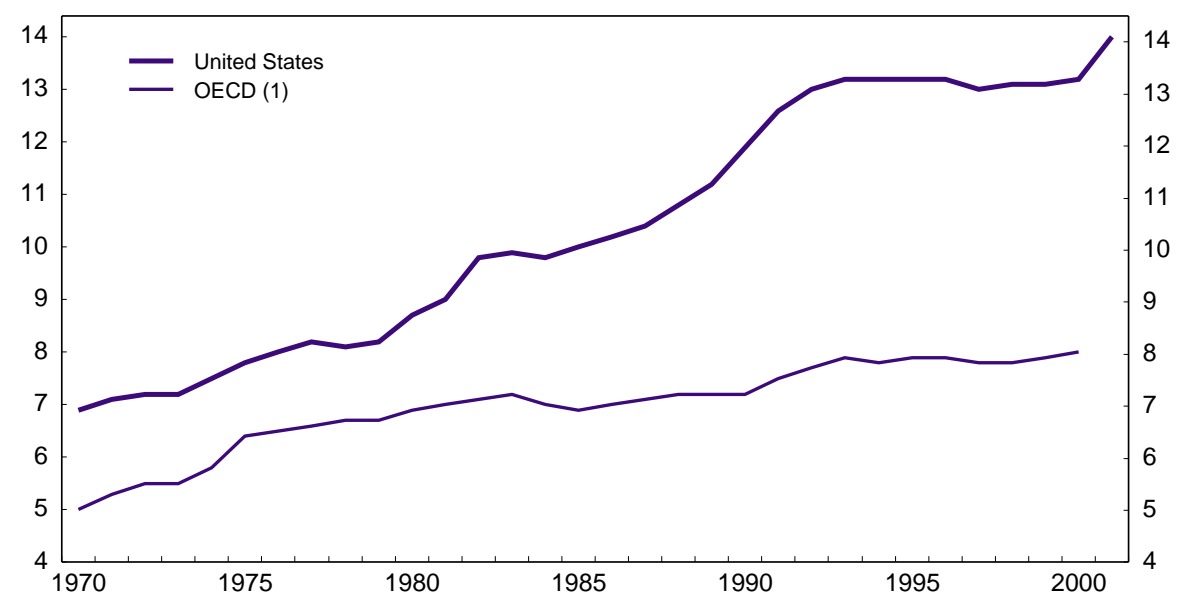

1. Unweighted average.

Source: Centers for Medicare and Medicaid Services (CMS) and OECD.

\section{Components and determinants of spending}

32. A relatively simple explanation for the high level of spending on health care in the United States is that the nation has a high level of total resources. OECD data show a close relationship between per capita GDP and per capita health expenditure in member countries: as a rule, countries with higher GDP per capita spend more on health care, which is, after all, a "normal good". Although this relationship is weaker for the most wealthy countries, US expenditure is abnormally high (Figure 4). Analysts endeavour, therefore, to obtain a more detailed understanding of the factors influencing the total amount and growth in US health spending over time. Such factors include those that affect both the volume of health care and the prices paid for it.

\section{Volume of medical services}

33. Simple data on service volume do not support the hypothesis that the quantity of services is the key factor explaining comparatively high US health spending. In fact, according to many available measures, US residents use a volume of medical services that is roughly comparable to those of other OECD countries, or even lower. For instance, US patients had an average of six annual physician visits in 1995, comparable with the range in most other OECD countries of five to seven visits, according to the OECD Health Database. Moreover, in 1996, 12 per cent of the US population was hospitalised, compared with 16 per cent in the median OECD country. ${ }^{30}$ US patients also had shorter hospital stays, and the average number of hospital days per capita of 1.1 in the United States was only half the OECD median of 2.2 days. Although these measures point to lower use of hospital care, they give an incomplete and

30. It must be noted, however, that OECD Health Data reflect only inpatient figures, although outpatient surgeries account for about half of all surgical procedures in the United States. 
potentially misleading picture because they do not take account of service intensity. Indeed, using the proxy measure of full-time-equivalent hospital employees per bed, the United States appeared highest among OECD countries in 1995 with a rate of just under 4 (with most others below 3 ).

34. Findings from various studies confirm the notion that US health care makes relatively intensive use of technology, e.g. the United States had more MRI units and CT scanners per person in 1999 than nearly three-fourths of OECD countries reporting data. Furthermore, a study comparing care for heart attack patients in 17 countries over the past decade (TECH Research Network, 2001) showed that, while treatment in all countries has become more intensive in the use of medications and cardiac procedures, the United States had a pattern of early adoption of new technologies and fast diffusion. Based on more limited evidence, Japan and possibly France also shared this pattern of technology use for heart attack care. By contrast, other countries showed either a late start/fast growth pattern of technological diffusion (Australia, Belgium and most Canadian provinces) or a late start/slow growth pattern (the United Kingdom, Scandinavian countries and Ontario). The patterns of diffusion for new, very high cost drugs were similar to those for intensive procedures, but no such patterns were observed for low-cost, easy-to-use medications.

Figure 6. Comparative price levels for final health expenditure, $1999^{1}$

$$
\mathrm{OECD}=100
$$

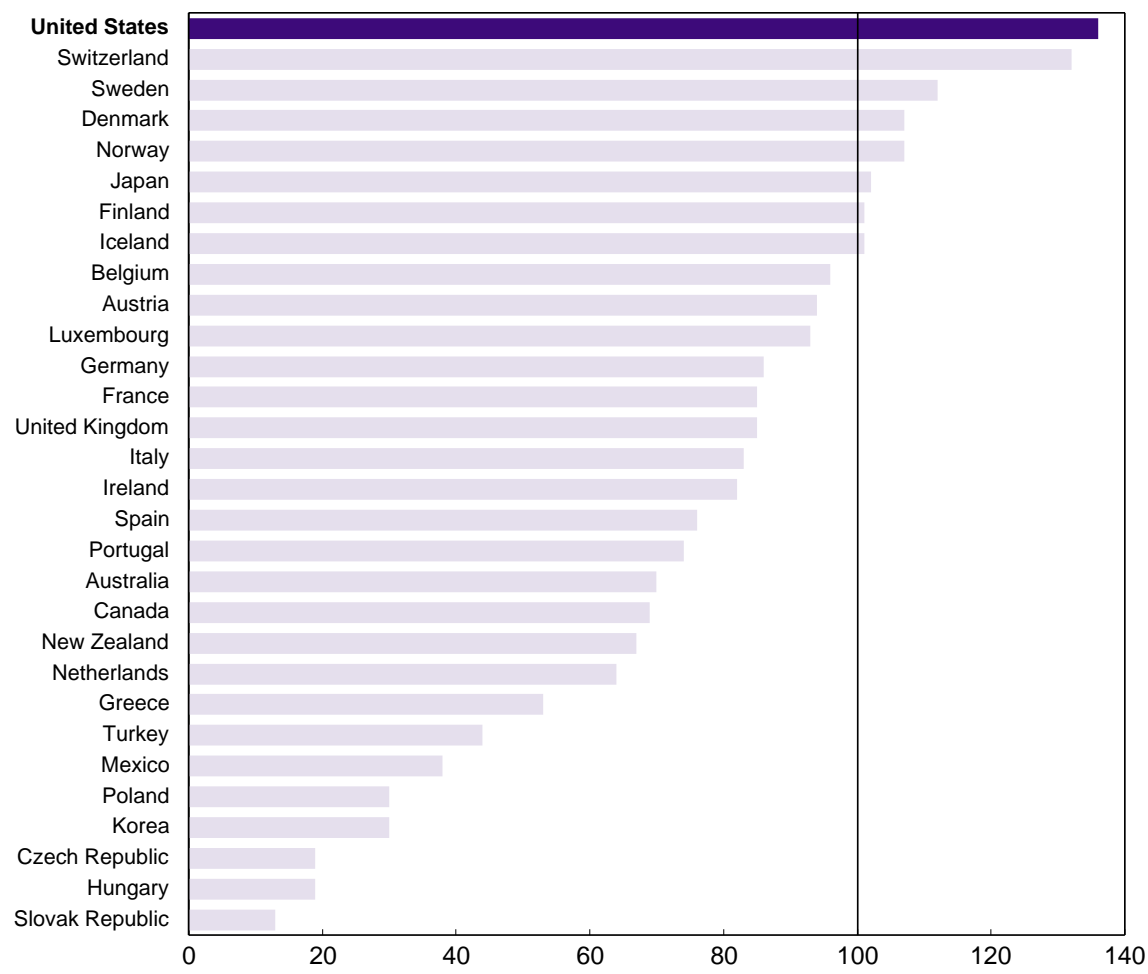

1. It should be noted that the figures presented are fragile, since making such comparisons for health expenditures is extremely difficult. Accordingly, the comparisons should be seen as approximations.

Source: OECD, Purchasing Power Parities and Real Expenditures, 2002.

Health care prices

35. While evidence regarding volumes is not very clear cut, there is no doubt that US prices for medical care commodities and services are significantly higher than in other countries and serve as a key 
determinant of higher overall spending. However, data problems abound in this area, and international comparisons are nearly always extremely fragile, especially when they encompass bread groups of commodities and services with substantially different quality across countries. Thus, the fact that US health-care prices appear to exceed the OECD average level by a large margin (Figure 6) should be interpreted with caution. Nevertheless, the specific case of prescription drug prices may be illustrative. Although the US population obtained 27 per cent fewer prescriptions, on average, than patients in the OECD median country in 1996, expenditure per person on pharmaceuticals was 41 per cent higher than in the OECD median country. Some of this cost difference may be explained by differences across countries in drug research spending and in the types of drugs commonly prescribed. ${ }^{31}$

36. What set apart the United States from other large OECD countries up to the early 1990s was the sharp increase in health-care prices compared with overall prices (Table 4). Given the different methodology and quality of such indicators, divergences between the United States and other OECD countries may be overstated, however. ${ }^{32}$ Relative healthcare deflators in the United States increased more slowly in the second half of the 1990s, perhaps reflecting the one-time effects of the expansion of managed care and the 1997 Balanced Budget Act. The medical care component of the Consumer Price Index (CPI) serves as another indicator of health price developments. Although it has been criticised for failing to take quality improvements and shifts in demand over time into account, which is a crucial issue, it provides timely information on recent trends. It grew by $41 / 4$ per cent in 2001, with hospital and related services showing the greatest price increase (61/2 per cent). Compared with the overall CPI, relative price increases of medical care slowed to $1 / 2$ per cent per year in the mid-1990s but have re-accelerated to almost 2 per cent since then.

Factors affecting volume and price of US health care

37. Analysts have long believed that the single greatest explanation for high US spending levels is the nation's investment in medical technology. Economists conjecture that technological progress has been responsible for as much as 75 per cent of the increase in health care expenditure over time (Newhouse, 1992 and 1993). Adoption of new technology results in more intensive service volume and increased use. It also contributes to price inflation, to the extent that early adoption is associated with paying higher introductory prices and to the extent that costlier new technologies replace, or are used in addition to, older, less expensive ones. However, these cost-increasing factors may be more than offset by improvements in health outcomes that new technologies can provide, and some experts maintain that appropriate adjustment for quality would show that some new technologies lead to lower prices (Cutler and McClellan, 2001 and Cutler et al., 1998).

38. Numerous other factors have been cited as determinants of the volume and price of US health care. Fee-for-service payments to physicians, common in Medicare and PPOs that serve a high share of the working population, provide incentives for increased service use. High levels of insurance coverage with low patient cost-sharing, have the same effect. Need for services, as indicated by the overall level of illness and disability (in part related to obesity), also play a key role in determining demand. Recent evidence suggests, however, that the overall health and disability status of older persons may be improving, which

31. See Danzon and Kim (1998) and Danzon (1999). Even here, the OECD has discontinued the collection and dissemination of data regarding the number of prescriptions because they were found to be problematic.

32. While it seems that the US deflator for medical services is biased upwards (Cutler et al., 1998), in Europe medical price trends are rather understated, according to OECD experts. 
Table 4. International comparison of health expenditure-related indicators Average growth rates

\begin{tabular}{|c|c|c|c|c|c|c|}
\hline & $1980-84$ & 1985-89 & $1990-94$ & $1995-99$ & $1980-90$ & $1990-2000$ \\
\hline \multicolumn{7}{|l|}{ Real expenditure ${ }^{1}$} \\
\hline Canada & 5.7 & 4.6 & 3.4 & 2.9 & 5.2 & 3.1 \\
\hline France & & & 3.3 & 2.1 & & 2.7 \\
\hline Germany & 2.5 & 2.3 & 7.3 & 2.8 & 2.6 & 5.3 \\
\hline Italy & & 2.9 & 1.5 & 1.9 & 4.5 & 2.1 \\
\hline Japan & 4.7 & 3.2 & 4.2 & 3.3 & 3.8 & 3.8 \\
\hline United Kingdom & 3.4 & 3.8 & 4.7 & 3.2 & 3.5 & 4.0 \\
\hline United States & 6.0 & 6.5 & 5.5 & 3.5 & 6.4 & 4.5 \\
\hline \multicolumn{7}{|l|}{ Relative prices $^{2}$} \\
\hline Canada & 1.1 & 0.5 & 1.2 & -0.1 & 0.9 & 0.4 \\
\hline France & & & -0.3 & 0.1 & & -0.1 \\
\hline Germany & 1.6 & -0.1 & 0.3 & 0.4 & 0.8 & 0.3 \\
\hline Italy & & 3.1 & 0.7 & -0.4 & 3.1 & 0.4 \\
\hline Japan & -0.4 & 1.2 & 0.4 & 1.5 & 0.4 & 0.8 \\
\hline United Kingdom & 2.1 & 1.3 & 2.1 & -0.6 & 1.6 & 1.3 \\
\hline United States & 3.2 & 2.8 & 2.3 & 1.0 & 3.0 & 1.6 \\
\hline \multicolumn{7}{|l|}{ Volume $^{3}$} \\
\hline Canada & 4.5 & 4.1 & 2.2 & 2.9 & 4.2 & 2.7 \\
\hline France & & & 3.6 & 2.0 & & 2.9 \\
\hline Germany & 1.0 & 2.4 & 7.0 & 4.9 & 1.8 & 6.4 \\
\hline Italy & & -0.3 & 0.7 & 2.3 & 1.3 & 1.7 \\
\hline Japan & 3.9 & 2.0 & 4.2 & 3.3 & 2.9 & 3.9 \\
\hline United Kingdom & 1.4 & 2.5 & 2.6 & 3.6 & 1.9 & 2.9 \\
\hline United States & 2.7 & 3.6 & 3.2 & 2.5 & 3.3 & 2.9 \\
\hline \multicolumn{7}{|l|}{ Real GDP } \\
\hline Canada & 2.1 & 3.8 & 1.2 & 3.5 & 2.7 & 2.6 \\
\hline France & 1.7 & 3.0 & 1.3 & 2.2 & 2.4 & 1.9 \\
\hline Germany & 1.2 & 2.9 & 4.9 & 1.5 & 2.3 & 3.2 \\
\hline Italy & 1.8 & 3.1 & 1.1 & 1.9 & 2.4 & 1.6 \\
\hline Japan & 3.0 & 4.7 & 2.2 & 1.3 & 4.0 & 1.8 \\
\hline United Kingdom & 0.9 & 3.9 & 1.4 & 2.8 & 2.3 & 2.2 \\
\hline United States & 2.4 & 3.6 & 2.2 & 3.8 & 2.9 & 3.1 \\
\hline
\end{tabular}

1. Nominal health care expenditure divided by the GDP deflator.

2. Price deflators for personal health care divided by the GDP deflator.

3. Nominal health expenditure divided by personal health care deflators.

Source: OECD Health Data, 2002 and OECD Economic Outlook.

may offset some of the effects of population ageing (Cutler, 2001) ${ }^{33}$ Although disputed in the literature, some analysts speculate that an oversupply of physicians, particularly in urban areas, results in a phenomenon known as induced demand, in which health care practitioners provide services that exceed their marginal benefits. The tort system, under which providers can be sued for malpractice and found civilly liable for damages resulting from negligence or error, is believed to induce physicians to err on the

33. Population ageing contributes to spending growth, as the elderly consume approximately three times as much health care as their under-65 counterparts. However, ageing has been less pronounced in the United States than elsewhere. 
side of doing tests to rule out even health problems with only a remote probability. That same system of compensating victims of malpractice results in premiums for professional liability that have driven up health care prices by affecting providers' costs of doing business. ${ }^{34}$ Kessler and McClellan (1996) found that malpractice reforms that directly reduce liability pressure on physicians lead to reductions of between 5 and 9 per cent in medical expenditures without substantial effects on mortality or medical complications. Finally, administrative costs account for a rising share of health expenditure (Table 3).

\section{Future expenditure trends}

39. Analysts generally agree that the outlook is for accelerating growth in private and public health spending. Actuaries from the US Department of Health and Human Services cite several factors portending an increase in health spending trends: rising health sector wages, legislation in 1999 that increased Medicare spending, reports of increasing insurance premiums, technology and consumer demand for less restrictive insurance plans (Centers for Medicare and Medicaid Services, 2002). Health expenditure is projected to grow from 14 per cent of GDP in 2001 to 17 per cent in 2011 (Table 5). The public share of overall health expenditures would continue to rise gradually, with public spending reaching 8 per cent of GDP at the beginning of the next decade.

Table 5. National health expenditure projections, 2001-11

\begin{tabular}{|c|c|c|c|c|c|}
\hline & 1980 & 1990 & 2000 & 2001 & 2011 \\
\hline \multicolumn{6}{|l|}{ National health expenditures } \\
\hline As a per cent of GDP & 8.8 & 12.0 & 13.2 & 14.0 & 17.0 \\
\hline Per capita (dollars) & 1067 & 2738 & 4637 & 5039 & 9216 \\
\hline \multicolumn{6}{|l|}{ Per cent distribution } \\
\hline Out of pocket & 23.7 & 19.7 & 15.0 & 14.8 & 14.1 \\
\hline Private insurance & 27.8 & 33.5 & 34.2 & 34.2 & 34.3 \\
\hline Public & 42.7 & 40.6 & 45.2 & 45.5 & 46.7 \\
\hline Federal & 29.0 & 27.7 & 31.7 & 31.8 & 31.6 \\
\hline State and local & 13.6 & 12.9 & 13.5 & 13.7 & 15.1 \\
\hline \multicolumn{6}{|l|}{ Memorandum items: } \\
\hline \multirow{2}{*}{$\begin{array}{l}\text { Relative medical price deflator } \\
\quad(1996=100) \\
\text { Population } 65 \text { years and older } \\
\quad \text { (per cent of total) }\end{array}$} & 66.1 & 89.6 & 103.5 & 105.2 & 115.7 \\
\hline & 11.2 & 12.3 & 12.5 & 12.5 & 13.0 \\
\hline
\end{tabular}

Source: Centers for Medicare and Medicaid Services, Office of the Actuary.

40. Although Medicaid spending has grown more strongly recently and is likely to continue to do so in the next few years (with pressures felt at the state and local level, the Medicare programme's financial condition has been the major source of concern among US policymakers. Such concern led to the establishment, in 1997 (as part of the BBA), of a bipartisan commission charged with studying long-term reform options for Medicare against the backdrop of the impending retirement of the baby boom generation. ${ }^{35}$ The Commission failed to reach the required super-majority regarding the changes needed,

34. With the stock market correction along with large legal awards eroding insurers' reserves, malpractice insurance premiums have surged, recently rising at a median annual rate of 15 per cent for general surgeons and nearly doubling for some specialists. Obstetricians are now paying as much as $\$ 100000$ a year to protect themselves, according to press reports. Some cases of outright withdrawal have occurred.

35. Of concern is the increase in the number of programme beneficiaries concurrent with a reduction in the relative number of workers financing the programme. 
however, and the adoption of reforms, including a prescription drug benefit, remains an unresolved political issue. This may in part reflect the fact that recent reports of the public trustees have a more optimistic outlook for Medicare's Hospital Insurance trust fund than in previous years. ${ }^{36}$ Since 1999, the trust fund's income has exceeded programme expenditures. Income increased significantly as a result of robust economic growth in the late 1990s and - due to the implementation of the BBA in 1997, efforts to combat fraud and abuse in the Medicare programme and a substantial decline in the utilisation of home health care services - trust fund expenditures actually slowed for a while. Despite the weaker economy and renewed rapid growth in expenditures due to subsequent legislation that increased provider payments, the trust fund again met the trustees' test of short-range financial adequacy in 2002. According to the trustees' estimates, the depletion date for the trust fund is now 2030, substantially further off than previous estimates. ${ }^{37}$ However, although the projected long-term (75 years) actuarial balance has also improved, the Hospital Insurance trust fund still fails by a wide margin to meet the trustees' test of long-range solvency. The trustees also urge policy makers to consider effective means of controlling rapidly rising costs for Medicare's Supplementary Medical Insurance (i.e. non-hospital costs). ${ }^{38}$ Moreover, because the Medicare benefits package is out of date (in particular with respect to drug coverage), there is considerable interest in finding ways to expand it without substantially worsening the programme's outlook.

\section{Unequal resource and service use}

41. The US health system aims to establish minimal access for the population as a whole that can be supplemented at the individual level. Use of services and allocation of resources range widely across the population on a number of dimensions other than health status and medical needs. Notable among these are insurance coverage, income, geographic location, race and sex.

\section{Access to care}

42. Although the rate of insurance coverage increased during the economic upswing in the late 1990s, it ended the decade below its 1990 level, continuing the downtrend observed in the 1980s. Characteristics of the uninsured population (Table 6) provide clues to assess ways to raise coverage. The uninsured population is disproportionately poor and near-poor. The vast majority of uninsured persons is employed or belongs to a working family (Fronstin, 2001c), but many of those who work are not offered insurance. ${ }^{39}$ Low-wage workers are at greater risk of being uninsured, as are unskilled labourers, service workers and those employed in small businesses. Children under 18 are more likely than adults to be insured, and their coverage actually improved over the 1990s (Mills, 2001). But the rate of coverage rate also varies significantly by age group. More than one quarter of 18 to 24 year-olds lack insurance coverage. Immigrants and persons of Hispanic ethnicity are also heavily over-represented among the uninsured. Those without insurance coverage have access to care, particularly emergency care, but they obtain less primary and preventive care.

36. Because it is a pay-as-you-go system, the balance of the trust fund has primarily symbolic import.

37. The estimated depletion date was 2015 in 1999, 2023 in 2000 and 2029 in 2001.

38. This part of Medicare, with no trust fund constraint, is about to exceed hospital costs.

39. There is evidence, however, that insurance coverage has declined primarily because increasing costs have led workers not to take up coverage even when offered it (Cutler, 2002). 
Table 6. Characteristics of the uninsured, 2000

\begin{tabular}{|c|c|c|c|}
\hline & Number (millions) & $\begin{array}{c}\text { As a percentage } \\
\text { of category }\end{array}$ & $\begin{array}{l}\text { As a percentage } \\
\text { of all uninsured }\end{array}$ \\
\hline Total uninsured & 38.7 & 14.0 & 100.0 \\
\hline \multicolumn{4}{|l|}{ Sex } \\
\hline Male & 20.2 & 14.9 & 52.1 \\
\hline Female & 18.6 & 13.1 & 47.9 \\
\hline \multicolumn{4}{|l|}{ Race and ethnicity } \\
\hline White & 29.3 & 12.9 & 75.6 \\
\hline Black & 6.6 & 18.5 & 17.1 \\
\hline Asian and Pacific Islander & 2.1 & 18.0 & 5.3 \\
\hline Hispanic (Hispanics can be of any race) & 10.8 & 32.0 & 28.0 \\
\hline \multicolumn{4}{|l|}{ Age } \\
\hline Under 18 years & 8.5 & 11.6 & 21.8 \\
\hline 18 to 24 years & 7.3 & 27.3 & 19.0 \\
\hline 25 to 34 years & 7.9 & 21.2 & 20.5 \\
\hline 35 to 44 years & 6.9 & 15.5 & 17.9 \\
\hline 45 to 64 years & 7.8 & 12.6 & 20.2 \\
\hline 65 years and over & 0.2 & 0.7 & 0.6 \\
\hline \multicolumn{4}{|l|}{ Region } \\
\hline Northeast & 6.0 & 11.4 & 15.5 \\
\hline Midwest & 6.8 & 10.8 & 17.5 \\
\hline South & 15.4 & 15.8 & 39.7 \\
\hline West & 10.6 & 16.7 & 27.3 \\
\hline \multicolumn{4}{|l|}{ Household income } \\
\hline Less than $\$ 25000$ & 13.9 & 22.7 & 35.9 \\
\hline$\$ 25000$ to $\$ 49999$ & 12.8 & 17.0 & 33.0 \\
\hline$\$ 50000$ to $\$ 74999$ & 6.5 & 11.0 & 16.8 \\
\hline$\$ 75000$ or more & 5.6 & 6.9 & 14.3 \\
\hline \multicolumn{4}{|l|}{ Education ( 18 years and older) } \\
\hline Total & 30.3 & 14.8 & 78.2 \\
\hline No high school diploma & 9.0 & 26.6 & 23.3 \\
\hline High school graduate only & 10.8 & 16.4 & 27.9 \\
\hline Bachelor's degree or higher & 3.4 & 7.1 & 8.9 \\
\hline \multicolumn{4}{|l|}{ Work experience (18 to 64 years old) } \\
\hline Total & 30.0 & 17.6 & 77.5 \\
\hline Worked during year & 22.8 & 16.2 & 58.9 \\
\hline Did not work & 7.2 & 23.6 & 18.7 \\
\hline
\end{tabular}

Source: US Census Bureau, Current Population Survey, March 2001.

Access to emergency care and basic services

43. Some assurance of access to care for emergency services is provided under US law. Hospital emergency departments are required to assess and stabilise any patient presented, irrespective of the person's insurance coverage or ability to pay. They serve as the treatment centre of last resort for those 
patients who do not have another source of care available. This is, however, an inefficient and expensive way of providing care that results in unnecessary spending on conditions that could have been prevented. Moreover, studies have shown that uninsured adults are much less likely to obtain health care. For example, Baker et al. (2000) found, after adjusting for differences in age, sex, health status and income, that uninsured persons are half as likely as those with insurance to receive care for a condition deemed by a physician to be highly serious and requiring attention. Those who lack insurance coverage are also at greater risk of not receiving preventive care and routine care for chronic conditions. Ayanian et al. (2000) found that adults who lacked insurance for a year or more were significantly less likely than their insured counterparts to obtain cancer screening, cardiovascular risk reduction and diabetes care. ${ }^{40}$

\section{Access to new technology}

44. The US health system provides ready access to the latest clinically effective technologies and treatments for those with adequate insurance or ability to pay. Depending on the type of health insurance arrangements, patients may be required to obtain prior authorisation, based on an assessment of medical necessity, from a gatekeeper physician or health plan employee. However, unlike many other OECD countries, the United States has virtually no waiting times for elective procedures, with the exception of organ transplants (due to donor shortages). ${ }^{41}$

45. Debates regarding coverage of new services in US health insurance plans and public programmes tend to focus on clinical effectiveness and on medical necessity in the case of individual patients. By contrast, few insurers or public programmes explicitly take evaluations of cost-effectiveness or cost-benefit ratios into account in making decisions about coverage of health services. The state of Oregon was the focus of considerable attention among analysts, economists, lawyers and ethicists in the early 1990s, when it implemented a programme to ration care for its Medicaid patients using a combination of information on clinical benefits and public opinion to assign relative rankings to services. Coverage of specific services is determined based on the total programme budget available.

\section{Variation and equity issues}

46. Significant geographic variation in the use of services and related expenditures has been well documented in the US health services research literature. ${ }^{42}$ Wennberg et al. (2002) highlighted examples of such variation in a recent report. ${ }^{43}$ The scope of the differences results in significant regional discrepancies

40. Although little work has been done to make international comparisons of access to care, survey research in five English-speaking countries sheds some light on differences in access perceived by the population. Schoen et al. (2000) found that the United States was similar to Australia and New Zealand, but dissimilar to Canada and Great Britain in terms of differences in perceived accessibility across income groups. Twoto three-fold differences were found between those with above- and below-average incomes on measures of difficulty in obtaining care, care-related financial problems and quality of service received.

41. Very few published studies have addressed waiting times for health care services in the United States; however, studies have documented shorter waiting times for cardiovascular procedures in US hospitals, as compared with other countries. See, for example, Carroll et al. (1995).

42. See, for example, Wennberg et al. (1989), which compared rates of discharge, readmission and length of stay between Boston, Massachusetts and New Haven, Connecticut, and found that, adjusted for health care needs, they were 47, 29, and 15 per cent, respectively, higher in Boston. A full compendium of such data is produced annually as The Dartmouth Atlas of Health Care in the United States.

43. First, the percentage of women aged 65 to 69 who obtained a mammogram in the past two years ranged from 21 per cent to 77 per cent across the nation's hospital referral regions. Second, the average number of 
in the levels of Medicare expenditures ${ }^{44}$ and there is no evidence of any relationship between available measures of health status and these variations. Even after correcting for differences in age, sex and racial composition, per capita spending in some areas is more than double that in others. These spending discrepancies, in turn, have been subject to much recent attention in light of their translation into differences in the availability of managed care plans and the benefits and cost-sharing relief they provide. Policymakers' response has been investment in both health services research geared toward a better understanding of the underlying reasons for variance in care and in tools for improving the practice of evidence-based medicine. The Agency for Healthcare Research and Quality (AHRQ), part of the US Department of Health and Human Services, serves as the current locus of funding and direction of such research.

47. Also of great concern to US policymakers is the growing evidence of inequity in the use of certain services by race and sex. One recent study documented the independent influence of both race and sex on physicians' decisions (Schulman et al., 1999). A new study of Medicare managed-care enrolees provided strong evidence that blacks are less likely to receive recommended clinical care for a number of conditions, controlling for other factors known to be important in determining service use (Schneider et al., 2002). Large differences have been documented in the use of surgical services by insured persons that could not be fully explained by differences in medical need (Schulman et al., 1999). The reasons underlying these differences in care, which result in either or both the overuse of services among some groups and the under-use among others, are not yet well understood, ${ }^{45}$ but could reflect patient preferences and organisational or systemic barriers. A federal mandate drawn up in 2000 by the Department of Health and Human Services set 2010 as the year by which any documented healthcare disparities should be eliminated.

48. Differences in use of medical services are not unique to the US system but are common in other OECD countries as well. Even among countries that provide universal, comprehensive insurance coverage, higher-income peoples tend to use specialist care more often than would be predicted based on their medical needs, while lower-income persons rely more often on generalist care (van Doorslaer et al., 2000). However, there is some evidence that other OECD nations have a more equitable distribution across the population of services obtained in relation to medical needs. ${ }^{46}$

visits to specialists for beneficiaries in the last six months of life ranged from two per decedent (in Mason City, Iowa) to more than twenty-five per decedent (in Miami, Florida).

44. The problem is most evident in the Medicare programme, where payments to health plans are still linked to payment levels in the traditional fee-for-service programme. As a result, health plans in certain areas are able to furnish prescription drug coverage and improved cost sharing, whereas in other areas plans have withdrawn from the market because they are unable to compete with the traditional programme at the established payment rate. The net result is that some beneficiaries have significantly more health care benefits - including covered services and lower cost sharing — available to them than do their counterparts living in a neighbouring county.

45. One recent study by Epstein et al. (2000) found evidence that some such differences may reflect differences across populations in the relative rate at which services are furnished beyond what is clinically appropriate (overuse) and the rate at which needed care is not furnished (under-use). Using retrospective review of medical charts, the researchers found that black patients with end-stage renal disease who were appropriate candidates for transplant surgery were less likely than their white counterparts to be referred for transplant evaluation, placed on a waiting list or undergo transplantation.

46. A study of 11 OECD countries found that in the United States and three others (Portugal, Austria and Greece) the poorest fifth of the population benefited from 20 to 30 per cent fewer physician visits than the richest fifth, after controlling for indicators of the level of medical need (van Doorslaer et al., 2002). 


\section{Unexceptional health outcomes and quality of care}

49. Although the United States devotes more resources to health care than any other OECD country, the population's overall health status is only mediocre. Population diversity and societal characteristics tend to mask the achievements of the US health system in terms of outcomes and quality of care, however. Focused analysis of health system performance for patients with particular medical conditions yields a more nuanced picture of comparative strengths and weaknesses. Assessment of appropriate service use provides a sense of how treatment patterns contribute to the achievement of desired outcomes.

\section{Population health status}

50. As in other OECD countries, life expectancy and infant mortality have improved considerably in the past decade, continuing a longer-term trend. Life expectancy at age 65 averaged 17.7 years in 1999, up from 17.2 years in 1990. Similarly, the US infant mortality rate (per 1000 live births) was 7.1 in 1999 , declining from 9.2 in 1990. The United States trails most other OECD countries by these measures,

Figure 7. Life expectancy and GDP per capita, 1999

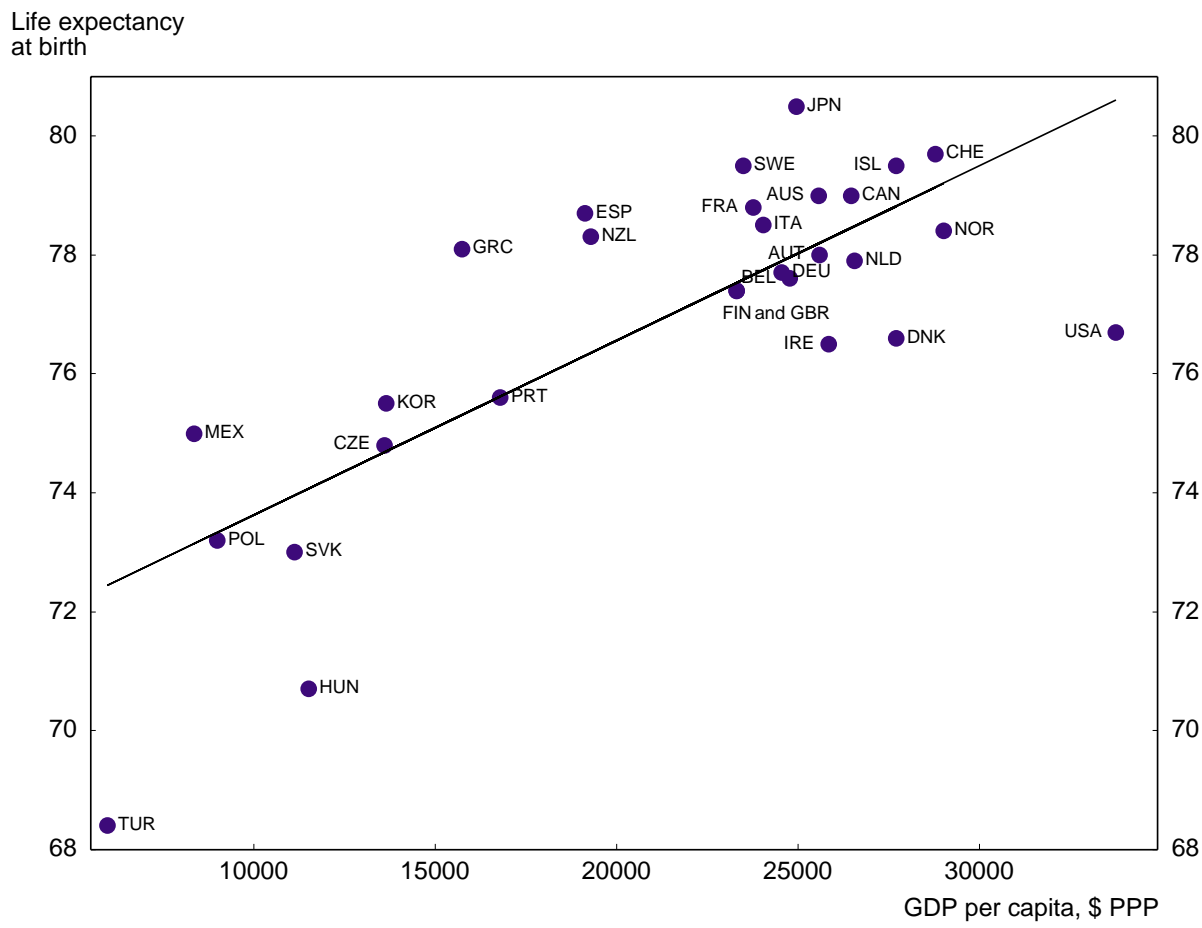

Note: The regression line is: Life expectancy $=70.69+0.0003$ * GDP per capita

$\mathrm{R}$ squared $=.59$

(67)

(6.2)

Source: OECD Health Data, 2002. 
however. ${ }^{47}$ Population health in the United States, as measured by these crude indicators, falls considerably short of what would be expected on the basis of the country's income level (Figure 7).

51. Of course, the population's health status is influenced by a wide range of factors in a complex way, and, in terms of both socio-economic characteristics and health-related behaviour, the United States differs significantly from many of its OECD counterparts. For instance, while it has achieved laudable results to date in reducing tobacco consumption, it suffers from the most acute and costly obesity problem of all OECD countries (Table 7) (Sturm, 2002). Factors such as drug use and crime rates also affect mortality rates. Econometric analysis suggests that the positive effect of high income and health expenditure in the United States may be partially offset by lower accessibility of some groups to health services as proxied by public expenditure shares; country-specific factors not captured in the regressions seem to account, however, for most of the gap in health status between the United States and better-performing countries (Annex II).

\section{Clinical outcomes}

52. When tied to a particular disease or clinical condition, health outcomes become more pertinent indicators of health system performance, because they provide information that can be used to determine the value of incremental spending. US researchers have undertaken numerous targeted studies of clinical outcomes that have focused on differences in morbidity and mortality across different populations (such as managed care enrolees and those insured under traditional arrangements, or patients who received different treatments for particular conditions). Summarising the research on the value of technological change for the treatment of five health conditions, Cutler and McClellan (2001) concluded that the total benefits of the changes exceeded the corresponding costs for at least four conditions over the periods studied. ${ }^{48}$ This study did not address whether similar benefits could have accrued from less costly investments. However, it found a clear and consistent association between more intensive treatment and better outcomes.

53. A number of studies have compared the outcomes of care furnished in the United States and Canada. One of them examined the use of invasive cardiac procedures and mortality rates for treatment of acute myocardial infarction, a form of ischaemic heart disease, among elderly patients (Tu et al., 1997). It found that the US patients were significantly more likely to undergo such procedures, but that long-term survival rates were equal in the two countries. ${ }^{49}$ The OECD's Ageing-related Diseases project has also shed some light on differences across countries in the outcomes of care provided to patients with particular conditions. A multi-country study of care for patients with ischaemic heart disease (Moise and Jacobzone, 2002) showed that US patients were most likely to undergo invasive cardiac procedures. At an aggregate level, several countries were equally successful in reducing mortality rates, mirroring the $\mathrm{Tu}$ et al. results. However, when disaggregated by age, health outcomes (measured as deaths one year from

47. There are limitations of such comparisons. For instance, US doctors tend to undertake drastic measures to save a troubled foetus. This leads to higher infant mortality rates relative to countries where efforts to save foetuses are not as great. On the other hand, in 1999, 17 per cent of mothers did not receive early prenatal care and 22 per cent of children aged 19-35 months had not received the recommended combined series of vaccinations (National Center for Health Statistics, 2001).

48. This study builds on previous work by Cutler et al. (1998) in which the quality-adjusted cost of treating heart attack patients was shown to have declined about 1 per cent annually between 1983 and 1994.

49. Other studies showed similar findings for post-surgical mortality and cancer survival (Roos et al., 1990; Roos et al., 1992; GAO, 1994). However, studies comparing acute myocardial infarction treatment and outcomes found that the United States attained better outcomes in patient functional status or quality of life (Roleau et al., 1993; Mark et al., 1994). 
hospitalisation for this illness) varied. The proportion of elderly US patients dying was slightly lower than in other countries, but some countries had somewhat better results for younger patients.

\section{Table 7. Tobacco consumption and obesity among OECD countries}

\begin{tabular}{|c|c|c|c|c|}
\hline & Toba & tion & & \\
\hline & Per cent $\mathrm{p}$ & ly smokers & Per ce & lation \\
\hline & $1990^{1}$ & $2000^{1}$ & $1990^{1}$ & $2000^{1}$ \\
\hline Australia & 28.6 & 22.8 & 8.7 & 20.8 \\
\hline Austria & 27.5 & 29.3 & 8.5 & \\
\hline Belgium & 32.0 & 31.0 & & 10.8 \\
\hline Canada & 28.2 & 19.8 & & 14.6 \\
\hline Czech Republic & 26.1 & 23.5 & 11.2 & 14.2 \\
\hline Denmark & 44.5 & 30.5 & 5.5 & \\
\hline Finland & 25.9 & 23.4 & 8.4 & 11.2 \\
\hline France & 28.5 & 27.0 & 6.5 & 9.6 \\
\hline Germany & 31.2 & 24.7 & & 11.5 \\
\hline Greece & 38.5 & & & \\
\hline Hungary & & 30.1 & & 19.4 \\
\hline Iceland & 30.3 & 22.9 & 16.5 & \\
\hline Ireland & 30.0 & 27.0 & & 10.0 \\
\hline Italy & 25.7 & 24.4 & & 8.6 \\
\hline Japan & 37.4 & 34.3 & 2.3 & 2.9 \\
\hline Korea & 34.6 & 33.5 & & 2.2 \\
\hline Luxembourg & 33.0 & 32.0 & & \\
\hline Mexico & 25.1 & & & \\
\hline Netherlands & 37.0 & 33.0 & 6.1 & 9.4 \\
\hline New Zealand & 28.0 & 25.0 & 11.1 & 17.0 \\
\hline Norway & 35.0 & 32.0 & & 6.0 \\
\hline Poland & 41.5 & & & \\
\hline Portugal & 19.0 & 20.5 & & 12.8 \\
\hline Slovak Republic & & & 18.9 & 16.2 \\
\hline Spain & 35.9 & 33.1 & 7.7 & 12.9 \\
\hline Sweden & 25.8 & 18.9 & 5.5 & 9.3 \\
\hline Switzerland & 34.0 & 33.0 & 5.3 & 6.8 \\
\hline Turkey & 43.6 & & & \\
\hline United Kingdom & 30.0 & 27.0 & 14.0 & 21.0 \\
\hline United States & 25.6 & 19.0 & 22.6 & 26.0 \\
\hline Median & 30.2 & 27.0 & 8.5 & 11.2 \\
\hline
\end{tabular}

1. Or nearest available year.

Source: OECD Health Data, 2002.

Processes of care

54. The quality of health care is a subject of considerable recent interest among US researchers and policymakers. ${ }^{50}$ Studying the under-use, overuse and misuse of services, analysts have documented

50. In 1998, health care quality was the subject of a report by a Presidential Commission. It is also the subject of an ongoing investigation by the Institute of Medicine and of current research sponsored by AHRQ and others. 
shortcomings and have made broad estimates of their effects on health outcomes and health care costs. Studies of a number of surgical procedures conducted in the late 1980s and early 1990s found rates of overuse ranging from 2 per cent to 40 per cent, although the methods used have been criticised both for potential bias and for the use of expert opinion in determining appropriateness (Phelps, 1993). ${ }^{51}$ The Institute of Medicine estimated that between 44000 and 98000 patients die in US hospitals each year as a result of medical errors and that the preventable adverse events that often result generate total annual costs of between $\$ 17$ and $\$ 29$ billion (Kohn et al., 2000).

55. The United States is attempting to address quality problems, and perhaps more so than other countries. In response to the above Institute of Medicine report, the Department of Health and Human Services has established a Patient Safety Task Force to identify and implement improvement strategies. ${ }^{52}$ Quality concerns have also prompted proposals to improve standardised measurement and reporting on health care quality; to invest in improved systems for collecting, storing and accessing data on health and health care; and to redesign health care delivery systems to increase the predictability and reliability of their outputs. The debate centres on whether measurement and reporting systems will be mandatory or voluntary, and how such information is to be used. The information could be used to set performance standards or to assist purchasers and consumers in making informed choices. It could also be used privately, on a voluntary basis, by plans and providers in taking steps to improve quality. Although a wide array of technical issues (such as the risk adjustment of findings on outcomes) and issues relating to privacy must be addressed, some of these recommendations are now being implemented.

\section{Summing up: strengths and weaknesses of the system}

56. Taken together, these findings suggest that the performance of the US health system has room for improvement on at least two counts. The first challenge is to minimise opportunity costs associated with the growth in health spending as a percentage of GDP by encouraging efficiency improvements. Given the dual role of technology as a driver of expenditure growth and a source of significant benefits to the United States and other nations, the role of insurance in fostering use of health care, and the malpractice system that heavily influences health spending, addressing this challenge in a sensitive way will be difficult. Another challenge will be to improve access to health care. Indeed, the large number of uninsured receive medical care at a rather late stage in their sickness.

57. Any proposals for improving the US health system should take into account its strengths while attempting to remedy its weaknesses. Although the system' complexity complicates reforms and adds to administrative costs, its diversity encourages technological advancement and permits consumer choice. Indeed, the system's responsiveness to consumer preferences, adaptability to innovations in health care financing and delivery, and ability to satisfy patients at an individual level have served to build support for the status quo. Therefore, focused efforts to address problems, rather than sweeping changes in the fundamental structure of the system, are more likely to gain public support. But this does not mean that more fundamental reforms would not be desirable.

51. Some limited international comparisons are available. One study of the provision of coronary angiography and bypass surgery in one Canadian and several American hospitals found higher rates of inappropriate service provision in the American hospitals studied (Roos et al., 1994). However, procedure rates were much lower in Canada, and the study did not address the extent of under-use, or the degree to which these procedures were not furnished to appropriate candidates in Canada versus the United States.

52. Moreover, using data from surveys and certification, the government has measured physical restraint use in nursing homes and set targets to decrease it to no more than 10 per cent. The target has been achieved and further reductions are now underway. 


\section{The agenda and prospective directions for reform}

58. Comprehensive reform has not been on the agenda of US policymakers since former President Clinton's proposal failed in 1994. Since then, policymakers in the Administration and the Congress have focused their attention on narrower health policy objectives, such as creation of SCHIP, the Health Insurance Portability and Accountability Act (HIPAA) and consideration of expanding Medicare to include outpatient prescription drug coverage. Policy proposals geared toward ensuring the long-term stability of Medicare have been the subject of great interest and heated debate but have made no headway. With a weaker economy, a deteriorating fiscal outlook, renewed strong growth in health spending and expectations for a resurgence in the number of uninsured, the environment for health policy has changed drastically. Despite this, there is no consensus and policy makers are still at loggerheads on the basic direction of reform. Thus, the outlook for reform of the US health system, and the shape it may take, remain uncertain. The remainder of this section reviews currently debated proposals and makes some recommendations for reform.

\section{Enhancing economic efficiency}

59. Current debate on reducing the rate of growth in health spending and of increasing its efficiency, both overall and in the Medicare programme, focuses on the question of the appropriate balance between regulation and competition as a means of achieving health system objectives, and there is strong disagreement about what strategies should be pursued. Policy makers are asking what is realistic to expect in terms of creating value-based competition among providers and health plans, given market failures, and what such competition could be expected to achieve. There is evidence that competition can improve efficiency, especially if the right incentives are in place, and help slow the growth in health costs to some degree (Annex III). At the same time, there is growing frustration with the difficulties of maintaining a regulatory environment, given the complexities of health care financing and delivery in the United States. Politicians are uncomfortable with the level of detailed administrative decision-making that occurs in a system that is regulated in this manner. Providers and plans are unhappy with the associated burden of compliance with regulatory requirements as administrative complexity increases. Notably, though, they seem to be also displeased with the oversight and control that private health plans and payers are able to exert in some markets.

\section{Commercial health insurance markets}

60. Policy proposals to control private health spending focus on improving the functioning of existing commercial insurance markets by reducing the subsidies that encourage over-consumption of health care and by fostering more consumer price sensitivity. A range of new products known as defined-contribution health insurance products has generated some interest among employers and policy-makers. They feature a medical savings account (MSA), contributions to which are tax-advantaged, paired with a major medical or supplementary policy for catastrophic care. They also tend to feature networks of providers paid on a fee-for-service basis and extensive use of Internet-based assistance to facilitate value-based purchasing of health care by individual consumers (Christianson et al., 2002). So-called "cafeteria-style" employee benefits plans, which would allow individual employees to determine how much of their total benefits package they wish to allocate toward health care versus other benefits, have been put forward as another option. There has as yet been little demand for such products and legal factors have restricted their development and use. There are concerns regarding their potential effect on broader risk-pooling among those of different health status. It has also been pointed out that they should be tax-advantaged only if families have satisfactory basic cover, including check-ups and preventive care. The Administration has proposed improvements to various of these arrangements, in particular making MSAs 
available to all employees, reducing the plan-deductible determining eligibility for tax breaks and increasing tax incentives. One recent innovation, Health Reimbursement Arrangements (HRAs), avoids many of the limitations of the MSAs. Such modifications are important to increase demand for these schemes and encourage broader participation.

61. The Administration is attempting to enhance individual choice and ownership of health coverage. It has proposed a tax credit to help those who do not have employer-provided insurance to purchase their own. It is working to loosen the restrictions on MSAs and to make them permanent. And, the IRS has issued a ruling determining the tax treatment of HRAs made by employers.

62. Breaking the link between employment and insurance coverage, which could occur with a change in tax policy, has also been proposed as a way of creating more individual choice and price sensitivity, purchase of insurance that is entirely portable, and tax equity. While this might indeed reduce over consumption, the impact on the number of uninsured is unclear. Nonetheless, there is no doubt that there are serious problems with the employer-based system. It contributes to job lock ${ }^{53}$ and excess costs attributable to administrative inefficiency, particularly for employers in the small-group market. Current tax concessions are both regressive and cost inflationary. Because of their unlimited nature they provide a strong incentive to favour health-care purchase over other forms of compensation and expenditure.

63. Improving private health insurance markets would improve efficiency but faces a number of obstacles. It is widely recognised that better information on health insurance options, plans, providers and treatments is needed to reduce the shrinking but still significant information asymmetries between consumers and other actors in the health system. Although efforts have been made to improve the availability of information, neither employers nor individual consumers have as yet incorporated information on plan performance into their purchasing and enrolment decisions to the extent expected by proponents of competition-based strategies (Marshall et al., 2000). As in other fields of specialised knowledge, some consumers may well need to use intermediaries to interpret information. Furthermore, the move toward increasingly large, overlapping provider networks reduces some of the distinctions across health plans that could potentially differentiate them in terms of quality of care. ${ }^{54}$

64. There have been few proposals addressing the issue of restraining the cost increases from technology use. As noted, high US relative technology costs have been shown to reflect its earlier adoption and more widespread application. Internationally comparative clinical outcome studies indicate that technology use for some conditions may be at a point of diminishing marginal returns in the United States, suggesting that different patterns of technology use could enhance efficiency. Such patterns are influenced by a variety of US health system features, both on the demand and supply side, notably a fear of health-care rationing and minimal controls on either availability or use. With better information and consumer choice, it is to be hoped that the least efficient technology applications will be eliminated.

65. With the managed-care approach apparently reaching its limits, there is a need to strengthen economic incentives for patients, providers and insurers to make more cost-effective decisions. Public policy can support this by encouraging the use of health-insurance products that combine coverage for essential care with defined-contribution arrangements (such as Medical Savings Accounts) that reward value-based purchasing for optional care and thus reduce over-consumption. To support cost-conscious

53. There is no agreement on the importance of job lock, however, nor on its significance for welfare (see Gruber and Madrian, 2002).

54. Some efforts to develop competition at the provider rather than the health plan level have emerged in response to these issues. For example, the Buyers Health Care Action Group of Minneapolis, Minnesota, has established a system of discrete provider groups to compete on cost and performance (Christianson and Feldman, 2002). 
decision-making, further efforts are also required to develop the information base on the relative performance of health plans and providers and the relative value of different treatments and technology use. To foster efficient application of health technologies, evidence-based assessment of their costs and benefits should be encouraged and made publicly available. To ensure that such information is taken into account, economic incentives might be used (such as co-payments, selective contracting with agreed providers and provider-reimbursement schemes). Continuing tough enforcement of anti-trust policies could also contribute to cost-effective use of new technologies and pharmaceuticals (Annex III). Finally, overuse of health-care services could be curbed by limiting subsidisation through the tax system (see below).

\section{Public programmes}

66. Reflecting the disparate views on competition and regulation, Medicare reform proposals that are meant to rein in health spending and increase efficiency may be separated into two groups. ${ }^{55}$ The first aims to allow private insurance markets a greater role in Medicare, reducing the programme's function as a direct purchaser of health care and increasing its importance as a conduit for and mediator of individual consumer transactions with plans. The second seeks to strengthen Medicare's ability to be a value-based purchaser of health care under the traditional component of the programme.

67. Proposals in the first camp contain a number of common elements. They would build upon the existing Medicare+Choice programme, which has established a means by which private health plans can participate in Medicare. They would require health plans to determine total premiums — through a bidding process, for example - and have the government separately determine the amount of its contribution to "premium support". Depending on how the amount of contribution to the premiums was determined and how the traditional programme was treated in the competitive structure, beneficiaries could face increased incentives to make cost-conscious decisions between the traditional programme and the private options available locally. These proposals seek to increase efficiency of Medicare spending by requiring beneficiaries to consider of the costs of their own choices in coverage and by fostering competition among health plans and the traditional programme. ${ }^{56}$

68. Such proposals, however, face many of the same challenges as do those to strengthen commercial insurance markets, with added challenges unique to Medicare. Programme beneficiaries are both less experienced than the working-age population in health plan decision-making and less equipped to serve as informed purchasers of health insurance and consumers of health care, despite their much greater use of services. For example, one recent study found that the elderly have much more difficulty accurately using comparative information to inform health plan choice than non-elderly peoples and that the differences are not explained by educational differences (Hibbard et al., 2001). However, Medicare beneficiaries are making choices, some with family assistance, and those who do not want to choose plans in the Medicare+Choice system can remain in the traditional system (where in fact they also already make choices regarding providers). Also, the technical problems relating to the establishment of health plan payments are considerable, given a population that includes very costly disabled and terminally ill patients, and the potential consequences of adverse selection. In addition to these constraints, there are concerns relating to the role the traditional programme will play in the competitive structure and to the ultimate effect on Medicare as a social insurance programme that furnishes a defined set of benefits to a specific population.

55. Articles by Vladeck (2001) and Wilensky (2001) provide two perspectives on Medicare reform issues.

56. An example of such a system is that existing for federal employees, which, in the Administration's view, could serve as a model for Medicare reform. See Council of Economic Advisers (2002) and Feldman et al. (2002). 
69. Finally, the existing Medicare+Choice scheme has failed to thrive, and there is bipartisan support to increase funding, correcting shortfalls since BBA. Based on research findings showing that Medicare+Choice programme enrolees are healthier, on average, than traditional programme enrolees, Congressional advisory bodies hold that plans have historically been overpaid in comparison with traditional programme costs. ${ }^{57}$ However, low payment updates since 1997 have mitigated this effect. The data needed to improve risk adjustment of premiums are costly for plans to collect, and implementation of improvements has been gradual. Some proposals call for breaking the link between Medicare+Choice programme payments and traditional programme spending, relying on a system of competition, negotiation or administered pricing under a revised formula to set payment rates. These approaches again raise unresolved questions about the role of the traditional programme under such schemes. Proposals generally call for fair competition between fee-for-service and private plans but differ on important details.

70. Proposals in the second camp also contain a number of common elements. Many would update Medicare's benefits package to include items commonly provided by private health insurers such as prescription drugs (Box 4) and preventive care. Such an expansion of benefits is also part of the Administration's framework for Medicare restructuring, which otherwise focuses on strengthening the programme's financial sustainability, providing better insurance options and deregulation (Box 5). Some proposals would increase the programme's ability to undertake selective contracting or otherwise differentiate among providers on the basis of performance. They would also change methods of paying for care so as to establish incentives for delivery of effective health care. However, these proposals are subject to both technical and political feasibility constraints. From a technical perspective, sensitive measures and data systems, along with selection criteria, must be developed to support active purchasing strategies. In terms of political feasibility, it may be difficult for the programme to exercise its monopsony power by excluding providers or treating them preferentially. Some recommendations geared toward reform of the traditional Medicare programme would also give beneficiaries more incentives to be more cost conscious in their spending on health care. Because of the high rate of first-dollar supplemental (Medigap) insurance coverage, most Medicare beneficiaries do not directly bear the costs of their service use. Some proposals suggest redesigning the regulated Medigap market to require policies to retain some cost sharing, perhaps in conjunction with redesign of Medicare's own cost-sharing arrangements.

\section{Box 4. Prescription drug coverage for Medicare beneficiaries}

A debate over implementing outpatient prescription drug coverage in Medicare has sprouted in recent years, even as the larger debate about fundamental reforms to Medicare remains unresolved.

About one-quarter of Medicare beneficiaries have no prescription drug coverage at all, and others have coverage that is limited by annual caps on benefits or greater cost sharing for drugs not included on health plan formularies. Nonetheless, programme beneficiaries accounted for 40 per cent of total drug spending in 1997. As a result of their levels of use and limited coverage, they paid about 45 per cent of their total prescription drug costs out of pocket in that same year (Crippen, 2001). With the expansion of demand for drugs and rising costs, along with the decline in private supplemental insurance coverage among beneficiaries, political pressure to furnish coverage to Medicare beneficiaries for prescription drugs has grown considerably in the last few years. A number of options for such a broadening in coverage have been debated.

As a temporary solution until a full drug benefit is implemented, the Administration has unveiled a short-term proposal to allow states to extend drug coverage to low-income senior citizens under Medicaid. Under the proposal, the federal government would allow states to expand Medicaid coverage of Medicare beneficiaries from the current 100 per cent of the federal poverty level up to 150 per cent. ${ }^{1}$ As an inducement to states, the federal government would pay 90 per cent of the costs that states would incur in expanding eligibility (rather than the usual

57. These organisations include the Congressional Budget Office, the General Accounting Office and the Medicare Payment Advisory Commission. 
cost sharing of around 60 per cent). Increasing coverage incrementally has obtained support from a range of political perspectives. Given current problems with state budgets, however, states may not be willing to take the pre-requisite step of expanding their programmes to include Medicare beneficiaries under 100 per cent of the poverty level, coverage for whom would be paid for only at the state's current matching rate. Independent estimates suggest that almost 70 per cent of eligible persons would get coverage.

Another option for coverage (also supported by the Administration) is to add a drug benefit to the Medicare package, which could be managed by private benefits managers. The cost of the benefit would, of course, depend largely on the generosity of the coverage and how the benefit was structured (for example, to provide stop-loss or first dollar coverage). However, the Congressional Budget Office projects that, even absent a drug benefit, prescription drug costs for Medicare beneficiaries will total \$113 billion (more than 1 per cent of GDP) in 2004, which makes the cost of full coverage significant, particularly if coverage increases consumption (Crippen, 2002).

Also possible is the complementary option of facilitating coverage by Medicare+Choice plans through subsidies, an approach that would not make the benefit uniformly available to all beneficiaries. In 2001 , nearly 40 per cent of beneficiaries did not have the option of enrolling in a Medicare+Choice plan because no plans served their local area.

1. Only 18 of the 50 states now furnish Medicaid coverage to Medicare beneficiaries with incomes under 100 per cent of the federal poverty level.

71. Proposals to restructure Medicare have important implications for Medicaid beneficiaries as well as the state programmes that serve them. As noted, Medicaid has become the major source of financing for long-term care for the elderly and non-elderly with disabilities, providing services often excluded from Medicare and private insurance. While demand for such services is rising strongly, budget constraints have

\section{Box 5. The Bush Administration's framework for Medicare reform}

In July 2001, the Administration released a set of principles intended to guide congressional development of an acceptable restructuring proposal:

- All seniors should have the option of a subsidised prescription drug benefit as part of modernised Medicare.

- Modernised Medicare should provide better benefits coverage for preventive care and serious illnesses.

- Today's beneficiaries and those approaching retirement should have the option of keeping the traditional plan with no changes.

- Medicare should provider better health insurance options, like those available to all Federal employees.

- Medicare legislation should strengthen the programme's long-term financial security.

- The management of traditional Medicare should be strengthened so that it can provide better care for seniors.

- Medicare's regulations and administrative procedures should be updated and streamlined, while the instances of fraud and abuse should be reduced.

- Medicare should encourage high-quality health care for all seniors.

Source: The President's Framework to Strengthen Medicare, White House news release, 12 July 2001. 
led nearly half of the states to consider cuts in Medicaid funding. This highlights the need for addressing the structural problems plaguing the programme. One reform proposal rejected in the mid-1990s was to provide funding to states in the form of block grants. ${ }^{58}$ Although concerns regarding the adequacy of the safety net would need to be addressed, this would both provide a stable financial base for, and allow the states to make innovative changes in, Medicaid programmes. An alternative would be to shift some of the burden of financing long-term care to other public or private payers.

72. In summary, with public health programmes facing cost increases that seem difficult for taxpayers to sustain, there is a need to step up reform efforts. In the case of Medicare, there is room for efficiency gains through reducing unnecessary care by harnessing the positive effects of competition among health plans and providers, although adequate protections for the elderly and disabled populations served by the programme must be maintained. While it can be argued that Medicare should provide the most effective treatments and services such as prescription drugs, the significant costs associated with enhanced benefits (up to 2 per cent of GDP by 2030) and the programme's long-run solvency are major considerations. Medicaid is struggling to maintain its expanded coverage in the face of strongly rising programme costs, particularly for prescription drugs. Placing the programme on a sound financial footing will require co-ordinated policies because it is the main payer for services not covered by Medicare or private insurance and because the programme provides coverage for populations that would otherwise lack insurance.

\section{Covering the uninsured}

73. There is general consensus in the United States that the instability and incompleteness of insurance coverage for the population is a serious problem, both for uninsured individuals and society as a whole. However, while there is general support for reducing the number of uninsured, there is considerable disagreement about which strategies to use to accomplish this objective. The basic options for increasing coverage are to build on existing public programmes or to facilitate additional private coverage. Initiatives of both types have been taken in the recent past, representing efforts to target different segments of the uninsured population. SCHIP, which built upon the existing Medicaid infrastructure, was created to expand coverage of uninsured children. The 1996 Health Insurance Portability and Accountability Act (HIPAA), by contrast, was designed to improve continuity of private coverage for persons undergoing a change in employment status. The Trade Act of August 2002 provides a credit for eligible individuals (who have been displaced by trade and retirees aged 55-64 who have lost retirement benefit due to employer bankruptcy) to purchase health insurance. The Administration has also proposed broader tax credits (see below).

74. Broadening eligibility for Medicaid and SCHIP is a possible approach for extending coverage to additional groups, such as more of the poor and near-poor. The recent SCHIP experience shows that this approach can have an impact on coverage, although a quarter of poor children remain uninsured. State budgetary pressures call further expansion of these programmes into question, however. Indeed, the states' share of health spending is projected to rise markedly over the next ten years or so.

75. In the past several years a number of proposals have been put forward to allow some early retirees under age 65 to buy into Medicare. However, there is a reluctance to enact such an expansion borne out of fiscal concerns and the desire not to put more health care under government control. Many such proposals target the 62-64 age group, given that Social Security eligibility begins at 62 and that this is the peak age of retirement from full-time work (Shea et al., 2001). Most of them would require

58. Such an approach would address the contentious issue of over-billing (in order to get inflated matching funds from the federal government). 
beneficiaries to pay in at the full cost to the government of supplying coverage, although some would provide for subsidies. Some proposals would hinge eligibility on income, while others would link to loss of employer-sponsored coverage. Although the age cohort that comprises many early retirees does not have a high non-coverage rate, this group can be especially hard hit by loss of coverage. Premiums for individually purchased policies rise steeply with age in most states, reflecting average health expenditures for the 55-64 age group that are double those of the 45-54 year-olds (Shea et al., 2001).

76. Tax credits that would serve to subsidise private purchase of health insurance on the individual market have been proposed by the Administration as a means of promoting coverage among some of the uninsured. Their effectiveness would depend on critical design issues, such as the amount of the tax credit relative to premium costs; extent of eligibility for the tax credit; whether the credit is refundable for those whose tax burden is less than the credit amount; whether it is "advanceable" (that is, available at the time insurance is actually purchased); and whether reforms to the individual market (for instance regarding community rating $)^{59}$ are included as part of such a policy. In addition to these design issues, analysts must consider the extent to which the availability of such tax credits would result in a reduction in employer-sponsored coverage and their impact on non-group insurance. The main issue for such proposals is the size of the tax credits relative to premium levels. The Administration's proposed health insurance tax credit, which phases out with income, would offer to pay a share of premium costs for purchasing private insurance meeting certain minimum standards with a ceiling of $\$ 1000$ for individuals and $\$ 3000$ for families. Estimates of the non-group premium for comprehensive coverage range from $\$ 1500$ to $\$ 2500$ for an individual, and $\$ 5000$ to $\$ 7000$ for a family. Hence, some studies predict only a modest impact of such a credit on net insurance coverage (Gruber and Levitt, 2000), while others (Pauly and Herring, 2001) consider that a credit between half and two-thirds of the premium could have the desired effects.

77. Some experts have proposed the replacement of the current (unlimited) tax exclusion with a system of tax credits. Although this would probably encourage lower-cost coverage and increase take-up rates by lower-income workers, policy makers have not pursued this option, on the grounds that it would have a significant impact on current plans, union negotiations and other issues affecting worker compensation. As noted, there is also a risk that the employer-sponsored risk pool would shrink. One variant that seems attractive would be to cap the existing tax exclusion in order to free up additional budgetary resources to allow a combination of public programme expansion and sufficiently generous credits that would have a significant coverage-enhancing effect. The credits could be integrated with the exclusion, depending on the design. Such an approach would not discriminate against employer-provided coverage, which is desirable if the number without insurance is not to increase.

78. To sum up, the experience of the past decade has shown that the US voluntary health insurance system as currently structured, has not achieved full coverage of the population, even during a prolonged economic upswing. Lack of coverage causes both health and economic problems for the uninsured. The two basic options available to achieve full coverage are to build on existing public programmes possibly going so far as a universal system, or to ensure that private coverage is available to the uninsured. Recent experience suggests that expanding the eligibility for public programmes to include more populations not well served by private insurance can be effective. However, this option is limited by budget constraints and a desire not to increase political control over health care. The introduction of a health tax credit to promote private insurance coverage among the uninsured could be helpful. This approach also has budget implications but would avoid expanded public control. Capping the unlimited tax exclusion of employer-furnished health benefits could partly offset budgetary cost of any new tax credit (and any expansion of public programmes). Finally, it must be emphasised that there is evidence to suggest that increased coverage - whether through either one of these options or a combination of both - is unlikely

59. Without community rating, selection problems might be exacerbated as healthier people might drop their current group coverage in order to reduce their premiums. 
to eliminate all disparities in quality and inequities across groups in the use of health services. Other policies are necessary to address this issue.

\section{Conclusions}

79. Ten years ago, an OECD review of the US health system concluded that it was doubtful whether mere marginal reforms could adequately deal with the problems facing it, namely soaring costs, low value for money relative to population health status and unsatisfactory coverage and access to health services. For a while, it seemed that this view was excessively pessimistic, but now it has become clear that the rise in managed care and the strong economy in the 1990s provided only a temporary respite. The discussion above has demonstrated that there are no easy solutions. Fundamental reform lacks sufficient political support. Indeed, the US system is seen domestically to have considerable advantages. Moreover, reform proposals, whether they favour competition or regulation, all have problematic side effects. Still, the ongoing issues facing the system need to be addressed. With managed care approaches to controlling costs reaching their limits, health spending is projected to accelerate, rising to 17 per cent of GDP in ten years and more than one-third of GDP in the longer term in the absence of corrective action (Council of Economic Advisers, 2002), the public component of which would be difficult for taxpayers to sustain. Because other countries achieve similar health outcomes at lower levels of expenditure, there may be opportunities to improve the efficiency of health care spending. As health care costs have been rising, the proportion of the population covered by health insurance has generally been falling, and a continuation of this trend is likely in the absence of new policy measures. Incomplete insurance coverage and delayed access to care adversely affects population health outcomes and possibly economic performance. Box 6 sets out some recommendations as to what could be the most promising avenues of reform, taking account of fiscal and institutional constraints that suggest that a multi-faceted approach may be required.

\section{Box 6. Recommendations concerning the health care system}

\section{Maximise efficiency and value for money}

- Cap the unlimited tax exclusion that supports private employer-sponsored insurance in order to reduce the overuse of health care services, without discriminating against employer-sponsored provision, and to help finance new tax credits for the uninsured.

- Promote health insurance products that combine defined-contribution arrangements (such as Health Reimbursement Arrangements and Medical Savings Accounts), which reward value-based purchasing and thus reduce over-consumption, with coverage for essential and catastrophic care.

- Increase efforts to develop information on health plan and provider performance and on the quality of care with a view to spurring value-based competition and improvement in health outcomes.

- Institute policies to encourage investment in cost-effective health technologies and to foster efficient application of such technologies.

- Ensure that the trend toward vertical and horizontal consolidation among health care providers and insurers does not adversely affect competition, consistent with US antitrust laws. More generally, aim to improve antitrust enforcement in the sector.

- Explore the enhancement of the efficiency of the Medicare programme through alternative health insurance options, while maintaining adequate protection for beneficiaries.

- Ensure that any enrichments of the Medicare programme (such as the proposed prescription drug benefit) do not jeopardise the programme's long-run solvency. 
- Reform the medical malpractice litigation system to reduce defensive medicine, enhance quality improvement efforts and restore the supply lost because of resulting cost increases.

\section{Improving insurance coverage and access to health care}

- Make sure that all Americans have health insurance coverage through a refundable tax credit to promote private insurance among the uninsured combined with expanded public programmes for those who lack private coverage.

- $\quad$ Explore additional ways to deliver care more efficiently in Medicaid and SCHIP.

- $\quad$ Research the causes of disparities in quality of care to design solutions consistent with US values. 
ECO/WKP(2003)4

\section{BIBLIOGRAPHY}

Ayanian, J.Z., J.S. Weissman, E.C. Schneider, J.A. Ginsburg and A.M. Zaslavsky (2000),

"Unmet Health Needs of Uninsured Adults in the United States", Journal of the American Medical Association, Vol. 284, No. 16, 25 October.

Baker, D.W., M.F. Shapiro and C.L. Schur (2000),

"Health Insurance and Access to Care for Symptomatic Conditions", Archives of Internal Medicine, Vol. 160, No. 9.

Baker, L.C., J.C. Cantor, S.H. Long and M.S. Marquis (2000),

"HMO Market Penetration and Costs of Employer-Sponsored Health Plans", Health Affairs, Vol. 19, No. 5, September-October.

Barro, R. and J. Lee (2000),

"International Data on Educational Attainment: Updates and Implications", Working Paper No. 42,

Center for International Development at Harvard University.

Capps, C., D. Dranove, S. Greenstein and M. Satterthwaite (2001),

"The Salient Majority Fallacy of the Elzinga-Hogarty Criteria: A Critique and New Approach to Analyzing Hospital Mergers", NBER Working Paper No. 8216, April.

Caroll, R.J., B. Soderfeldt, B.C. James and L. Malmberg (1995), "International Comparison of Waiting Times for Selected Cardiovascular Procedures", Journal of the American College of Cardiology, Vol. 25, No. 3, 1 March.

Centers for Medicare and Medicaid Services (2002), National Health Expenditures, March.

Chernew, M., G. Gowrisankaran and D.S. Scanlon (2001),

"Learning and the Value of Information: The Case of Health Plan Report Cards", NBER Working Paper 8589, November.

Christensen, S. and J. Shinogle (1997),

"Effects of Supplemental Coverage on Use of Services by Medicare Enrolees", Health Care Financing Review, Vol. 19, No. 1, Fall.

Christianson, J., R. Feldman, and D. Wholey (1997),

"HMO Mergers: Estimating Impact on Premiums and Costs", Health Affairs, Vol. 16, No. 6,

November/December.

Christianson, J.B. and R. Feldman (2002),

"Evolution in the Buyers Health Care Action Group Purchasing Initiative", Health Affairs, Vol. 21, No. 1, January/February. 


\section{ECO/WKP(2003)4}

Christianson, J.B., S.T. Parente and R. Taylor (2002),

"Defined-Contribution Health Insurance Products: Development and Projections", Health Affairs, Vol. 21, No. 1, January/February.

Connor, R., R. Feldman, B. Dowd and T. Radcliff (1997),

"Which Types of Hospital Mergers Save Consumers Money?", Health Affairs, Vol. 16, No. 6, November/December.

Council of Economic Advisers (2002),

Health Insurance Credits, Unpublished Working Paper, February.

Crippen, D. (2001),

Statement of Dan L. Crippen, Director, Congressional Budget Office, Medicare Reform: Providing Prescription Drug Coverage for Seniors, before the Committee on Energy and Commerce Subcommittee on Health, US House of Representatives, 16 May (updated 18 July 2001).

Crippen, D. (2002),

Statement of Dan L. Crippen, Director, Congressional Budget Office, Projections of Medicare and Prescription Drug Spending, before the Committee on Finance, US Senate, 7 March.

Cunningham, P.J., J.M. Grossman, R.F. St. Peter and C.S. Lesser (1999), "Managed Care and Physicians' Provision of Charity Care", Journal of the American Medical Association, Vol. 281, No. 12, 24-31 March.

Cutler, D.M., M. McClellan, J.P. Newhouse and D. Remler (1998),

"Are Medical Prices Declining? Evidence from Heart Attack Treatments", Quarterly Journal of Economics, Vol. 113, No. 4, November.

Cutler, D.M. and R.J. Zeckhauser (2000),

"The Anatomy of Health Insurance", in A. Culyer and J. Newhouse (eds.), Handbook of Health Economics, Elsevier, Amsterdam.

Cutler, D.M. and M. McClellan (2001),

"Is Technological Change in Medicine Worth it?", Health Affairs, Vol. 20, No. 5, September/October.

Cutler, D.M. (2001),

"Declining Disability Among the Elderly", Health Affairs, November/December.

Cutler, D.M. (2002),

"Employee Costs and the Decline in Health Insurance Coverage", NBER Working Paper No. 9036, July.

Danzon, P. and J. Kim (1998),

"International Price Comparisons for Pharmaceuticals: Measurement and Policy Issues", Pharmaco Economics.

Danzon, P. (1999),

"Price Comparisons for Pharmaceuticals: A Review of US and Cross-National Studies", Washington, DC.

Deaton, A. and D. Lubotsky (2001),

"Mortality, Inequality and Race in American Cities and States", NBER Working Paper No. 8370, July. 
Deaton, A. and C. Paxson (2001),

"Mortality, Education, Income, and Inequality among American Cohorts", in D.A. Wise (ed.), Themes in the Economics of Aging, University of Chicago Press, Chicago.

Deininger, K. and L. Squire (1996),

“A New Data Set Measuring Income Inequality”, World Bank Economic Review, Vol. 10.

Dranove, D., D. Kessler, M. McClellan and M. Satterthwaite (2002),

"Is More Information Better? The Effects of "Report Cards" on Health Care Providers", NBER Working Paper No. 8697.

Draper, D.A., R.E. Hurley, C.C. Lesser and B.C. Strunk (2002),

"The Changing Face of Managed Care", Health Affairs, Vol. 21, No. 1, January/February.

Eichner, M., M. McClellan and D. Wise (1997),

"Health Expenditure Persistence and the Feasibility of Medical Savings Accounts", Tax Policy and the Economy, Vol. 11.

Epstein, A.M., J.Z. Ayanian, J.H. Keogh, S.J. Noonan, N. Armistead, P.D. Cleary, J.S. Weissman, J.A. David-Kasdan, D. Carlson, J. Fuller, D. Marsh and R.M. Conti (2000),

"Racial Disparities in Access to Renal Transplantation-Clinically Appropriate or Due to Underuse or Overuse?", New England Journal of Medicine, Vol. 343, No. 21.

Feldman, R., K.E. Thorpe and B. Gray (2002), "Policy Watch: The Federal Employees Health Benefits Plan", Journal of Economic Perspectives, Vol. 16, No. 2, Spring.

French, H.E. (1996),

Competition and Monopoly in Medical Care, AEI press, Washington DC.

Fronstin, P. (2001a),

"Employment-Based Health Benefits: Trends and Outlook", Employee Benefit Research Institute Issue Brief No. 233, May.

Fronstin, P. (2001b),

"Sources of Health Insurance and Characteristics of the Uninsured: Analysis of the March 2001 Current Population Survey", Employee Benefit Research Institute Issue Brief No. 240, December.

Gabel, J.R., P.B. Ginsburg, J.D. Pickreign and J.D. Reschovsky (2001),

"Trends in Out-of-Pocket Spending by Insured American Workers, 1990-1997", Health Affairs, Vol. 20, No. 2, March/April.

Gabel, J.R., L. Levitt, J. Pickreign, H. Whitmore, E. Holve, D. Rowland, K. Dhont and S. Hawkins (2001), "Job-Based Health Insurance in 2001: Inflation Hits Double Digits, Managed Care Retreats", Health Affairs, Vol. 20, No. 5, September/October.

Gabel, J.R., K. Dhont, H. Whitemore and J. Pickreign (2002), "Individual Insurance: How Much Financial Protection Does it Provide?", Health Affairs, (web exclusive), April.

Gaynor, M. and G.F. Anderson (1995),

"Uncertain Demand, the Structure of Hospital Costs, and the Cost of Empty Hospital Beds", Journal of Health Economics, Vol. 14, No. 3, May/June. 
Gaynor, M. and D. Haas-Wilson (1999),

"Change, Consolidation, and Competition in Health Care Markets", Journal of Economic Perspectives, Vol. 13, Winter.

Gaynor, M. and W. Vogt (2000),

"Antitrust and Competition in Health Care Markets," in A. Culyer and J. Newhouse (eds.), Handbook of Health Economics, Elsevier, Amsterdam.

Given, R. (1996),

"Economies of Scale and Scope as an Explanation of Merger and Output Diversification Activities in the Health Maintenance Organization Industry", Journal of Health Economics, Vol. 15, No. 6.

Glied, S. (2000),

"Managed Care", in A. Culyer and J. Newhouse (eds.), Handbook of Health Economics, Elsevier, Amsterdam.

Gold, M.R. (2001),

"Medicare+Choice: An Interim Report Card", Health Affairs, Vol. 20, No. 4, July/August.

Gross, D.J., L. Alecxih, M.J. Govspam, J. Corea, C. Caplan and N. Bramgan (1999), "Out-of-Pocket Health Spending by Poor and Near-Poor Elderly Medicare Beneficiaries", Health Services Research, Vol. 34, April.

Grossman, M. (1999),

“The Human Capital Model of the Demand for Health", NBER Working Paper 7078, April, forthcoming in Handbook of Health Economics.

Gruber, J. and L. Levitt (2000),

"Tax Subsidies for Health Insurance: Costs and Benefits," Health Affairs, Vol. 19, No. 1, January/February.

Gruber, J. and B.G. Madrian (2002),

"Health Insurance, Labor Supply, and Job Mobility: A Critical Review of the Literature", NBER Working Paper 8817, March.

Hamoudi, A. and J. Sachs (1999),

"Economic Consequences of Health Status: A Review of the Evidence", Center for International Development at Harvard University, mimeo.

Hibbard, J.H., P. Slovic, E. Peters, M.L. Finucane and M. Tusler (2001),

"Is the Informed-Choice Policy Approach Appropriate for Medicare Beneficiaries?", Health Affairs, Vol. 20, No. 3, May/June.

Hitiris, T. and J. Posnett (1992),

"The Determinants and Effects of Health Expenditure in Developed Countries", Journal of Health Economics, Vol. 11, No. 2, August.

Hwang, W., W. Weller, H. Ireys and G. Anderson (2001),

"Out-of-Pocket Medical Spending for Care of Chronic Conditions", Health Affairs, Vol. 20, No. 6, November/December.

Kaiser Commission on Medicaid and the Uninsured (2001a),

Fast Facts, Henry J. Kaiser Family Foundation, Washington, DC, April. 
Kaiser Commission on Medicaid and the Uninsured (2001b),

"Medicaid Coverage During a Time of Rising Unemployment", Policy Brief, December.

Kawachi, I. and B.P. Kennedy (1997),

"The Relationship of Income Inequality to Mortality: Does the Choice of Indicator Matter?", Social Science \& Medicine, Vol. 45, No. 7.

Kenney, G. and J. Haley (2001),

"Why Aren't More Uninsured Children Enrolled in Medicaid or SCHIP?", Urban Institute policy brief series B, No. B-35, Washington, DC, May.

Kessler, D.P. and M.B. McClellan (1996),

“Do Doctors Practice Defensive Medicine?", Quarterly Journal of Economics, Vol. 111, No. 2, May.

Kessler, D.P. and M.B. McClellan (1999),

"Designing Hospital Antitrust Policy to Promote Social Welfare", NBER Working Paper, No. 6897, January.

Kessler, D.P. and M.B. McClellan (2000),

"Is Hospital Competition Socially Wasteful?", Quarterly Journal of Economics, Vol. 115, No. 2, May.

Kessler, D.P. and M.B. McClellan (2001),

"The Effects of Hospital Ownership on Medical Productivity", NBER Working Paper, 8537, October.

Kohn, L.T., J.M. Corrigan and M.S. Donaldson (eds.) (2000),

To Err Is Human: Building A Safer Health System, National Academy Press, Washington, DC.

Levit, K., C. Smith, C. Cowan, H. Lazenby and A. Martin (2002),

"Inflation Spurs Health Spending in 2000”, Health Affairs, Vol. 21, No. 1, January/February.

Levitt, L. and M. Freeland (2002),

"National Medical Care Spending", Health Affairs, Vol. 21, No. 2, March.

Luft, H. and R. Miller (1997),

"Does Managed Care Lead to Better or Worse Quality of Care?", Health Affairs, Vol. 16, No. 5, September/October.

Manheim, L.M., G.J. Bazzoli and M.-W. Sohn (1994),

"Local Hospital Competition in Large Metropolitan Areas", Journal of Economics and Management Strategy, Vol. 3, No. 1, Spring.

Mark, D.B., C.D. Naylor, M.A. Hlatky, R.M. Califf, E.J. Topol, C.B. Granger, J.D. Knight, C.L. Nelson, K.L. Lee, N.E. Clapp-Channing, W. Sutherland, L. Pilote, and P.W. Armstrong (1994), "Use of Medical Resources and Quality of Life after Acute Myocardial Infarction in Canada and the United States", New England Journal of Medicine, Vol. 331, No. 17, October.

Marshall, M.N., P.G. Shekelle, S. Leatherman and R.H. Brook (2000),

"The Public Release of Performance Data: What Do We Expect to Gain? A Review of the Evidence", Journal of the American Medical Association, Vol. 283, No. 14, 12 April.

Medicare Payment Advisory Commission (2000),

"Medicare Beneficiaries' Access to Quality Health Care", Report to Congress: Medicare Payment

Policy, MedPAC, March. 
Mills, R. (2000),

"Health Insurance Coverage: 2000", US Bureau of the Census Current Population Report, September.

Moise, P. and S. Jacobzone (2002),

"Comparing Treatments, Costs and Outcomes for Heart Disease in OECD Countries", Labour Market and Social Policy Occasional Papers No. 58.

National Center for Health Statistics (2001),

Health, United States, 2001, Department of Health and Human Services, Center for Disease Control and Prevention, Hyattsville, Maryland, August.

Newhouse, J.P. (1992),

"Medical Care Costs: How Much Welfare Loss?", Journal of Economic Perspectives, Vol. 6, No. 3, Summer.

Newhouse, J.P. (1993),

"An Iconoclastic View of Health Cost Containment", Health Affairs, Vol. 12 (supplement).

Newhouse, J.P. (1996),

"Reimbursing Health Plans and Providers: Selection versus Efficiency in Production", Journal of Economic Literature, Vol. 34, No. 3, September.

Newhouse, J.P., W.G. Manning, E.B. Keeler and E.M. Sloss (1989),

"Adjusting Capitation Rates Using Objective Health Measures and Prior Utilization", Health Care

Financing Review, Vol. 10, No. 3, Spring.

Nordhaus, W.D (2002),

"The Health of Nations: the Contribution of Improved Health to Living Standards", NBER Working Paper 8818, March.

OECD (1992),

Economic Survey of the United States, November, Paris.

Or, Z. (2000),

"Determinants of Health Outcomes in Industrialised Countries: A Pooled, Cross-Country, Time-Series Analysis", OECD Economic Studies, No. 30.

Pauly, M.V. (1998),

"Managed Care, Markets, and Monopsony", upublished Working Paper, University of Pennsylvania.

Pauly, M.V. and B. Herring (2001),

"Expanding Coverage Via Tax Credits: Trade-offs and Outcomes", Health Affairs, Vol. 20, No. 1, January/February.

Phelps, C.E. (1993),

"The Methodologic Foundations of Studies of the Appropriateness of Medical Care", New England Journal of Medicine, Vol. 329, No. 17, 21 October.

Philipson, T. and R. Posner (2001),

"Antitrust and the Not-For-Profit Sector", NBER Working Paper No. 8126, February.

Pollitz, K., N. Tapay, E. Hadley and J. Specht (2000),

"Early Experience with 'New Federalism' in Health Insurance Regulation”, Health Affairs, Vol. 19, No. 4, July/August. 
Pritchett, L. and L.H. Summers (1996),

"Wealthier is Healthier", Journal of Human Resources, Vol. 31, No. 4.

Robinson, J.C. and H. Luft (1985),

"The Impact of Hospital Market Structure on Patient Volume, Average Length of Stay, and the Cost of

Care", Journal of Health Economics, Vol. 4.

Robinson, J.C. (1996),

"Decline in Hospital Utilization and Cost Inflation Under Managed Care in California", Journal of the American Medical Association, Vol. 6, No. 13, 2 October.

Roos, L.L., E.S. Fisher, S.M. Sharp, J.P. Newhouse, G. Anderson and T.A. Bubolz (1990), "Post-surgical Mortality in Manitoba and New England, Journal of the American Medical Association, Vol. 263, No. 18.

Roos, L.L., E.S. Fisher, R. Brazauskas, S.M. Sharp and E. Shapiro (1992),

"Health and Surgical Outcomes in Canada and the United States", Health Affairs, Vol. 11, No. 2,

Summer.

Roos, L.L., R. Bond, C.D. Naylor, M.R. Chassin and A.L. Morris (1994),

"Coronary Angiography and Bypass Surgery in Manitoba and the United States: A First Comparison",

Canadian Journal of Cardiology, Vol. 10, No. 1, January-February.

Rothschild, M. and J.E. Stiglitz (1976),

"Equilibrium in Competitive Insurance Markets: An Essay on the Economics of Imperfect Information", Quarterly Journal of Economics, Vol. 90.

Rouleau, J.L., L.A. Moyé, M.A. Pfeffer et al. (1993),

"A Comparison of Management Patterns After Accute Myocardial Infarction in Canada and the United States", New England Journal of Medicine, Vol. 328, No. 11.

Royalty, A.B. and N. Solomon (1999),

"Health Plan Choice: Price Elasticities in a Managed Competition Setting," Journal of Human Resources, Winter.

Schneider, E.C., A.M. Zaslavsky and A.M. Epstein (2002),

"Racial Disparities in the Quality of Care for Enrolees in Medical Managed Care", Journal of the American Medical Association, Vol. 287, No. 10, 13 March.

Schoen, C., K. Davis, C. Desroches, K. Donelan and R. Blendon (2000),

"Health Insurance Markets and Income Inequality: Findings from an International Health Policy Survey", Health Policy, Vol. 51.

Schulman, K.A., J.A. Berlin and W. Harless (1999),

"The Effect of Race and Sex on Physicians' Recommendations for Cardiac Catheterization", New England Journal of Medicine, Vol. 340, No. 8, 25 February.

Shea, D.G., P.F. Short and M.P. Powell (2001),

"Betwixt and Between: Targeting Coverage Reforms to Those Approaching Medicare", Health Affairs, Vol. 20, No. 1, January/February.

Short, P.F. and J.S. Banthin (1995),

"New Estimates of the Underinsured Younger than 65 Years", Journal of the American Medical Association, Vol. 274, No. 16, October. 
Smith, J. (1999),

"Health Bodies and Thick Wallets: The Dual Relation Between Health and Economic Status", Journal of Economic Perspectives, Vol. 13, No. 2.

Sturm, R. (2002),

"The Effects of Obesity, Smoking and Drinking on Medical Problems and Costs", Health Affairs, Vol. 21, No. 2, March/April.

Technological Change in Health Care (TECH) Research Network (2001),

"Technological Change Around the World: Evidence from Heart Attack Care", Health Affairs, Vol. 20, No. 3, May/June.

Thornton, J. (2002),

"Estimating a Health Production Function for the US: Some New Evidence", Applied Economics, Vol. 34, No. 1, January

Trude, S., J.B. Christianson, C.S. Lesser, C. Watts and A.M. Benoit (2002),

"Employer-Sponsored Health Insurance: Pressing Problems, Incremental Changes", Health Affairs, Vol. 21, No. 1, January/February.

Tu, J.V., C.L. Pashos, C.D. Naylor, E. Chen, S.L. Normand, J.P. Newhouse, B.J. McNeil (1997),

"Use of Cardiac Procedures and Outcomes in Elderly Patients with Myocardial Infarction in the United States and Canada", New England Journal of Medicine, Vol. 336, No. 21, 22 May.

US General Accounting Office (1994),

"Cancer Survival: An International Comparison of Outcomes", Government Printing Office, Washington, DC.

Van Doorslaer, E. et al. (1997),

"Income-related Inequalities in Health: Some International Comparisons", Journal of Health Economics, Vol. 16, No. 1.

Van Doorslaer, E., X. Koolman and F. Puffer (2000),

"Equity in the Use of Health Care in Europe and the US", Journal of Health Economics, Vol. 19, No. 5.

Van Doorslaer, E., X. Koolman and F. Puffer (2002),

"Equity in the Use of Physician Visits in OECD Countries: Has Equal Treatment for Equal Need Been Achieved?", Chapter 11, Measuring Up: Improving Health Systems Performance in OECD Countries, Proceedings of the Ottawa Conference, November 2001.

Vladeck, B. (2001), "Learn Nothing, Forget Nothing — The Medicare Commission Redux", New England Journal of Medicine, Vol. 345, No. 6, 9 August.

Wennberg, J.E., E.S. Fisher and J.S. Skinner (2002),

"Geography and the Debate Over Medicare Reform", Health Affairs, web exclusive, 13 February.

Wennberg, J.E., J.L. Freeman, R.T. Shelton and T.A. Bubolz (1989),

"Hospital Use and Mortality Among Medicare Beneficiaries in Boston and New Haven", in the New England Journal of Medicine, Vol. 321, No. 17, 26 October.

Wilensky, G. (2001),

"Medicare Reform - Now is the Time", New England Journal of Medicine, Vol. 345, No. 6, August. 
Wilkinson, R.G. (1992),

"Income Distribution and Life Expectancy", British Medical Journal, Vol. 304, January.

Wilkinson, R.G. (1996),

Unhealthy Societies: The Afflictions of Inequality, Routhledge, London.

Woolhandler, S. and D.V. Himmelstein (2002),

"Paying for National Health Insurance - And Not Getting It", Health Affairs, Vol. 21, No. 4, July/August. 


\section{ANNEX I}

\section{REGULATION OF HEALTH INSURANCE AND PROVISION}

The health insurance industry is regulated by states, which results in some diversity of approaches, although the National Association of Insurance Commissioners develops model legislation and regulation in key areas that provide a common framework used by many states. In general, the philosophy underlying insurance regulation is pro-competitive. Nevertheless, states do impose a variety of requirements pertaining to financial solvency, quality assurance, benefits and other characteristics of insurance products. Most large employers self-fund their health benefits programmes and are thus exempt from state regulation, including patients' bills of rights that have been enacted in several states.

The regulation of private "Medigap" policies designed to supplement Medicare coverage is an exception to general insurance regulation standards in certain respects. Congress enacted legislation in 1989 in an effort to correct failures in the market for such insurance, such as beneficiaries purchasing numerous duplicative policies. ${ }^{1}$ Despite these regulations, the Medigap market is recognised as problematic in that the plans offering prescription drug coverage experience significant adverse selection, and thus high premium costs, and the design of the permitted benefits package may not well represent the current preferences of either consumers or policy makers.

An important, recent development in the regulation of private health insurance is the enactment of the Health Insurance Portability and Accountability Act (HIPAA) of 1996. This law established certain insurance portability standards and renewal protections designed to promote continuous insurance coverage for persons at risk of a break in coverage. ${ }^{2}$ It is believed to have affected the small-group insurance market more so than the individual market, primarily because it established insurance accessibility requirements without addressing the rating rules that determine premium amounts and, thus, affordability (Pollitz et al., 2000).

There is great variation across states in how regulation affects the market for health care provision. Each state sets its own level and type of regulation. States are responsible for regulating the delivery of health care. They establish license and certification requirements for hospitals, physicians and other providers. Some states also regulate to ensure access in under-served areas or to avoid perceived oversupply of certain services (through certificate-of-need regulations, for example). States in general rely on the tradition of professionalism as a form of self-regulation to create and promote voluntary compliance with standards of performance and accountability. ${ }^{3}$ As a side-effect of this approach, the ability of

1. Under the law, insurers are authorised to sell only 10 standardised plans. In addition, insurers are required to issue these policies, without any medical underwriting, to beneficiaries upon their becoming eligible for Medicare at age 65 and under other circumstances set in law.

2. It applies to consumers in federally and state-regulated health plans as well as self-funded employer plans. Examples of changes made under the law included reduced opportunities for insurers to apply pre-existing condition exclusions to new enrolees, provided those enrolees had maintained continuous coverage.

3. For example, accreditation by private oversight entities is widely sought by hospitals and other health care providers as a seal of approval recognised as meeting standards surpassing minimum state certification 
consumers and public officials to obtain information on performance of health care providers of all types was very limited up until the past five years or so. In recent years, however, providers have begun to respond to demands for information, partly in an effort to avert further prescriptive regulatory requirements.

requirements. In fact, accredited hospitals are in many cases deemed to have met state license and public programme certification requirements. In addition, physicians conduct quality review activities that have legal protections against disclosure of potentially incriminating information. 


\section{ANNEX II}

\section{POPULATION HEALTH DETERMINANTS IN A PANEL OF OECD COUNTRIES}

Econometric analysis can shed some light on the causes of cross-country differences in aggregate health outcomes. The relationship of a number of potential health determinants is explored using a panel of 30 OECD countries in the period of 1965-99. The focus is on life expectancy at birth and infant mortality, which are the most widely available measures of the health status of a population at the national level.

\section{The model}

A linear regression linking health outcomes to plausible correlates is estimated. One interpretation of this regression is that it represents a production function in which health is an output that is produced by a set of inputs, although the estimates could also simply be viewed as summarising the partial correlations between health outcomes and the variables examined. Specifically, the following regression equation is estimated by using a fixed-effects model:

$$
H_{i, t}=\beta_{0}+\beta_{1} I_{i, t-T}+\beta_{2} F_{i, t-T}+\beta_{3} E_{i, t-T}+\beta_{4} M_{i, t-T}+\beta_{5} X+v_{i}+\varepsilon_{i, t}
$$

where $i$ is the country, $t$ is the time period, and $T$ is a time lag, taken to be five years. ${ }^{1} H_{i, t}$ is the measure of health outcome. $v_{i}$ is a country-specific fixed effect and $\varepsilon_{i, t}$ is a mean zero, finite variance error.

$I$ is the log of real GDP per capita in 1995 US dollars using purchasing power parity exchange rates. Numerous studies have found a positive relationship between income and health outcomes for different time periods and country samples (for example, Or, 2000; Hamoudi and Sachs, 1999; Pritchett and Summers, 1996). ${ }^{2}$ However, some studies suggest that beyond some threshold level, additional income may have a diminishing impact on health (Wilkinson, 1992).

The fertility rate $(F)$ is included because there is some evidence of a potential link between demographic factors and health outcomes such as life expectancy or infant mortality (for example, Hamoudi and Sachs, 1999). A priori, lower fertility rates can be associated with better nutrition and

1. Since changes in health outcomes are most likely to be gradual over time, panel data are used where the observations are at five-year intervals. The dependent variables are observed at most eight times for each country: 1965, 1970, 1975, 1980, 1985, 1990, 1995 and 1999. The explanatory variables refer to variables observed roughly five years prior to these years since any causal relationship between changes in health outcomes and its determinants is less likely to be contemporaneous. That is, it is reasonable to view factors as influencing health outcomes only with some time lags.

2. Strong evidence in this respect for the United States is provided by Deaton and Paxson (2001) and Thornton (2002). 
parental care, leading to lower infant mortality rates as well as longer life expectancy, other things being equal. $^{3}$

A large economic literature suggests that individuals with higher levels of education $(E)$ can produce health more efficiently by increasing health knowledge and improving the ability to process health information (Grossman, 1999). Also, ethnographic studies show almost universally that at the household level, women provide most of the direct care for children. This is taken into account by separately controlling for education attainment in the male and female population.

$M$ is an indicator of medical resources. One can expect increasing health care spending to be related to better health outcomes, assuming that a greater amount of resources leads to an improvement in the level and the quality of health care services available. ${ }^{4}$ Apart from total health expenditure as a share of GDP, the share of public expenditure in total health expenditure is included to proxy the degree of availability and accessibility of health services. This approach has been used in most studies, given the difficulties in obtaining internationally comparable data (in particular for coverage; see Or, 2000).

$X$ is a vector of other health determinants. Income inequality can be harmful to population health through various channels. ${ }^{5}$ Life-style factors such as cigarette and alcohol consumption and environmental factors such as the extent of urbanisation, unemployment and air pollution are also considered. Finally, the country-specific fixed effect captures time-invariant differences in health outcomes across countries. Factors that may evolve very slowly over time, such as racial disparities in health-care use (emphasised in Deaton and Lubotsky, 2001) would be reflected in the fixed effect.

\section{Results}

Table A1 displays regression results for life expectancy and infant mortality based on selected specifications. Column 1 shows a version of the life expectancy equation that excludes the vector $X$. The estimated coefficients have in general the expected sign, although they are not always statistically significant. After controlling for income inequality (Column 2), the public spending share becomes significant, while total health expenditure becomes insignificant. Regression results for infant mortality are broadly consistent with those for life expectancy. Most notably, however, educational attainment (especially female) seems to be more important in explaining the variation in infant mortality rates across OECD countries than that in life expectancy (see Columns 3-4). Again, income per capita is one of the most important determinants of infant mortality, although other variables also enter the regressions with significant coefficients. If additional regressions are added, the results do not change significantly and are therefore not reported.

3. Similarly, one might expect a negative correlation between population growth and health outcomes, if rapid population growth is associated with lower access to medical care. But this hypothesis was not tested here.

4. Hitiris and Posnett (1992) report a significant negative impact of health expenditure on mortality rates in a panel of 20 OECD countries for the period of 1960-87. However, some studies find that the impact of medical care is very small or even positive in the United States (see Thornton, 2002, for example).

5. The channels through which income inequality is associated with a worse health status include under-investment in human capital, loss of social cohesion and dis-investment in social capital, and potentially harmful consequences of stress brought about by relative deprivation. Van Doorslaer et al. (1997) report that income inequality is closely related to inequalities in mortality or in morbidity. See Wilkinson (1996) and Kawachi and Kennedy (1997) for evidence and Smith (1999) for skepticism. 
Using the panel regression results, it is possible to assess the relative importance of potential health determinants and explain why the United States lags behind many OECD countries by these measures. Table A2 presents a decomposition of population health outcomes of the United States compared with the top five OECD countries using the regressions shown in Columns 2 and 4 of Table A1. In particular, the low share of public expenditure in total health expenditure - possibly and speculatively proxying for a low degree of availability and accessibility to health care ${ }^{6}$ - is an important correlate of the low life expectancy in the United States relative to the better performing OECD countries. For example, the low public share in health expenditures is estimated to be associated with a reduced life expectancy (in logarithms) of 0.0217 , which is 52.6 per cent of the life expectancy gap between the United States and the five leading OECD nations. On the other hand, relatively high US income per capita and health expenditure relative to GDP are estimated to contribute (in logarithms) positively to life expectancy and negatively to the infant mortality rate. However, a significant caveat to the results is that country-specific factors not captured in the regressions seem to account for most of the actual gap in health status between the United States and five best-performing OECD countries.

6. The conclusion is especially speculative since the figures exclude the tax expenditure from exclusion of employer-provided health insurance and because the relative level of US public spending is so much greater than its relative share of total health spending. 
ECO/WKP(2003)4

Table A1. Fixed effects model of population health

\begin{tabular}{|c|c|c|c|c|}
\hline \multirow[b]{2}{*}{ Independent variables } & \multicolumn{2}{|c|}{ Dependent variable: log of life expectancy at birth } & \multicolumn{2}{|c|}{ Dependent variable: $\log$ of infant mortality rate } \\
\hline & 1 & 2 & 3 & 4 \\
\hline Income per capita & $\begin{array}{c}0.0568 * \\
(9.06)\end{array}$ & $\begin{array}{c}0.0758 * \\
(9.10)\end{array}$ & $\begin{array}{l}-0.8102 * \\
(-8.76)\end{array}$ & $\begin{array}{c}-1.1260 * \\
(-5.10)\end{array}$ \\
\hline Fertility & $\begin{array}{l}-0.0115 * \\
(-3.17)\end{array}$ & $\begin{array}{l}-0.0092 * * \\
(-2.09)\end{array}$ & $\begin{array}{c}0.1828 * \\
(4.17)\end{array}$ & $\begin{array}{l}0.1-38 * * * \\
(1.74)\end{array}$ \\
\hline Female education & $\begin{array}{r}0.0070 \\
(0.72)\end{array}$ & $\begin{array}{r}0.0053 \\
(0.33)\end{array}$ & $\begin{array}{r}-0.2398 \\
(-1.13)\end{array}$ & $\begin{array}{c}-0.5630 * \\
(-3.02)\end{array}$ \\
\hline Male education & $\begin{array}{r}-0.0067 \\
(-0.59)\end{array}$ & $\begin{array}{r}-0.0017 \\
(-0.10)\end{array}$ & $\begin{array}{r}0.0614 \\
(0.27)\end{array}$ & $\begin{array}{r}0.3537 \\
(1.61)\end{array}$ \\
\hline Total health expenditure & $\begin{array}{l}0.0042 * \\
(2.59)\end{array}$ & $\begin{array}{r}0.0018 \\
(1.03)\end{array}$ & $\begin{array}{c}-0.0810 * \\
(-3.99)\end{array}$ & $\begin{array}{r}-0.0410 \\
(-1.47)\end{array}$ \\
\hline Public share in health expenditure & $\begin{array}{r}0.0366 \\
(1.46)\end{array}$ & $\begin{array}{l}0.0617 * * * \\
(1.81)\end{array}$ & $\begin{array}{r}0.1579 \\
(0.69)\end{array}$ & $\begin{array}{r}-0.1280 \\
(-0.42)\end{array}$ \\
\hline Income inequality & & $\begin{array}{r}-0.0002 \\
(-0.65)\end{array}$ & & $\begin{array}{l}-1 \mathrm{E}-03 \\
(-0.23)\end{array}$ \\
\hline Number of observations & 168 & 119 & 162 & 115 \\
\hline
\end{tabular}

Note: The reported standard errors of the coefficients are based on the White heteroskedasticity-consistent covariance matrix, which reduces the sensitivity of inference and hypothesis testing using OLS estimators of heteroskedasticity. The Wald test for group-wise heteroskedasticity strongly rejects the null hypothesis of homoskedasticity. White heteroskedasticity-consistent t-statistics are reported in parentheses. Levels of significance are indicated by asterisks: $*$ 1 per cent; ** 5 per cent; *** 10 per cent.

Definitions of variables: Income per capita $=\log$ of real GDP per capita, PPP; Fertility = fertility rate (average number of children per women of age 15-49); Female education $=\log$ of average years of secondary schooling in the female population (age of 15 and over) from Barro-Lee (2000); Male education $=$ log of average years of secondary schooling in the male population (age of 15 and over) from Barro-Lee (2000); Total health expenditure $=$ percentage of total health expenditure in GDP; Public share in health expenditure = share of public expenditure in total health expenditure; Income inequality = Gini coefficients, high quality data observations from Deininger and Squire (1996).

Source: OECD (unless otherwise specified). 
Table A2. Population health accounting ${ }^{1}$

\begin{tabular}{|c|c|c|c|c|c|}
\hline & $\begin{array}{l}\text { United States } \\
\text { - Top Five }\end{array}$ & $\begin{array}{l}\text { Percentage } \\
\text { of the gap }\end{array}$ & & $\begin{array}{l}\text { United States } \\
\text { - Top Five }\end{array}$ & $\begin{array}{l}\text { Percentage } \\
\text { of the gap }\end{array}$ \\
\hline Log of life expectancy at birth & -0.0412 & & Log of infant mortality & 0.5769 & \\
\hline Explained & -0.0336 & & Explained & 0.5544 & \\
\hline Income per capita & 0.0108 & -26.3 & & -0.2558 & -44.3 \\
\hline Fertility & -0.0031 & 7.6 & & 0.0257 & 4.5 \\
\hline Female education & -0.0012 & -3.0 & & -0.2031 & -35.2 \\
\hline Male education & 0.0003 & 0.8 & & 0.1041 & 18.1 \\
\hline Total health expenditure & 0.0078 & -19.0 & & -0.1936 & -33.6 \\
\hline Public health expenditure share & -0.0217 & 52.6 & & 0.0496 & 8.6 \\
\hline Income inequality & -0.0011 & 2.6 & & 0.0081 & -1.4 \\
\hline Country specific factors ${ }^{3}$ & -0.0273 & 66.4 & & 1.0356 & 179.5 \\
\hline Residual & -0.0076 & & & 0.0226 & \\
\hline
\end{tabular}

1. The top five healthiest countries in terms of life expectancy are Japan, Sweden, Canada, Switzerland, Norway and the top five countries in terms of infant survival are Finland, Sweden, Norway, Japan and France. The decomposition of the contribution to the difference in health outcomes from individual determinants is based on regression results in Columns 2 and 4 of Table A1.

2. Percentage of the actual gap between the United States and the top five countries in (logs of) life expectancy and infant mortality.

3. Not otherwise accounted for

Source: OECD. 
ECO/WKP(2003)4

\section{ANNEX III}

\section{COMPETITION IN HEALTH CARE MARKETS}

The social welfare implications of competition in health care have long been the subject of heated debate on both theoretical and empirical grounds. The conventional wisdom is that both health care and health insurance are substantially different from the textbook case of perfectly competitive markets, mainly because they are characterised by adverse selection and moral hazard, as well as poor consumer information. The assessment of the social welfare effects of increased competition has important policy implications. If competition improves social welfare, then strict regulation of anti-competitive activity and mergers may be socially beneficial. In any case, policymakers have to decide on the extent of competition they wish to see (and the implications for consumer choice), in what areas it should be encouraged (among health plans and/or providers), over which dimensions it should play a role (price and/or quality) and what sorts of restrictions (such as price floors or quality standards) should be implemented. In this annex the objective will be to give a brief summary of the theory and evidence on the impact of competition in this sector.

A fundamental problem in the health care market is that individuals have more information about their risk types than insurers (Rothschild and Stiglitz, 1976). This informational asymmetry can lead to an adverse selection problem. Studies suggest that the resulting welfare losses can be substantial (Cutler and Zeckhauser, 2000). High-risk individuals may purchase complete coverage, whereas low-risk patients may buy incomplete coverage or opt not to buy any at all. However, there is some evidence that most consumers are not dipping in and out of the insurance market as their health prospects change (Royalty and Solomon, 1999). ${ }^{1}$ Insurance companies may seek out good risks while avoiding bad risks, which is known as "cream skimming". There is also some evidence that HMOs have tended to enrol healthier individuals, compared to traditional fee-for-service plans (Newhouse, 1996).

Moral hazard is another widely recognised distortion in health care markets. It can arise if insurance changes patient behaviour, leading them to consume health services beyond a socially optimal level. In this case, competition may not be the first-best solution, and market power on the part of firms selling health services could increase social welfare by raising prices and restricting output (French, 1996; Pauly, 1998). This is based on the assumption that competitive pricing in insurance markets does not adjust to deal with moral hazard (such as through consumer cost sharing), an assumption that may not be valid (Gaynor and Haas-Wilson, 1999).

There is also concern that consumers are often poorly informed about the quality of health care providers or plans and also prices, so that increased competition in health care markets may lead to lower quality of care or the under-provision of necessary health services (Gaynor and Haas-Wilson, 1999). Several mechanisms can serve to improve consumers' knowledge of the quality of care. For instance, the use of the Internet can empower patients by providing them with information. With the growth of managed

1. Consumers tend to show persistence in their health spending arrangements lasting four years or even longer (Newhouse et al., 1989; Eichner et al., 1997). 
care, there has been renewed interest in measuring the quality of care. For example, quality report cards developed by private groups and public payers are increasingly used to measure the quality of managed care plans. While it is not yet clear how effectively consumers can use available information, one recent study indicates that health plan information can have a significant effect on consumer choice (Chernew et al., 2001). ${ }^{2}$ In principle, increased information on quality can not only help consumers make informed choices but also strengthen market functions by encouraging competition based on quality and by allowing payments to be linked to performance measures, such as treatment outcomes.

The hypothesis has been advanced that hospitals in more competitive markets will engage in a medical arms race on facilities or quality in order to attract consumers and physicians who bring customers with them. As a result, competition among hospitals may produce an excessive supply of care with its marginal value less than its marginal social costs (Robinson and Luft, 1985). However, this concern has been reduced in recent years as increased price competition among hospitals along with the rapid growth of managed care seems to have improved social welfare (Kessler and McClellan, 2000; Gaynor and Haas-Wilson, 1999). Analysing longitudinal Medicare claims data for elderly non-rural beneficiaries hospitalised with cardiac illness over the period of 1984-94, Kessler and McClellan (2000) show that hospital competition has unambiguously improved social welfare since 1990. That is, it has led both to substantially lower costs and significantly lower rates of adverse health outcomes, while in the 1980s it had entailed higher costs and, in some cases, higher rates of adverse outcomes. ${ }^{3}$ In states with high HMO enrolment rates, welfare gains have been uniformly larger. In a related study by Kessler and McClellan (2001), for-profit hospitals are shown to have important spillover benefits on medical productivity. Areas with a presence of for-profit hospitals are found to have lower expenditures, but virtually the same patient health outcomes.

With the rise in managed care, health care markets have seen waves of strategic alliances, mergers and acquisitions, and integration. If this trend continues, many markets are expected to be dominated by a few large firms in the near future, with increased risks of exercise of market power. This portends an increasing role of antitrust policy in health care markets. Since 1980, the US Department of Justice and Federal Trade Commission (FTC) have initiated 136 antitrust cases in the health care sector (Philipson and Posner, 2001). ${ }^{4}$ Although there is still much to learn about the implications of health market consolidations (such as their implications for the responsiveness of the system to external changes in demand, technology and other forces and for dimensions of health care such as quality of care or consumer choice), on balance they may not all be socially optimal, even if they generate efficiency gains - for a literature survey on this issue, see Gaynor and Vogt (2000).

2. But Dranove et al. (2002) find evidence that the effects of report cards are unclear in the case of Coronary Artery Bypass Graft surgery adopted by New York and Pennsylvania in the early 1990s.

3. Reviewing the existing empirical literature on the consequences of competition in markets for hospital services in the United States, they observed an interesting pattern, supporting their own results: $i$ ) research based on data prior to the mid-1980s finds that competition among hospitals tended to lead to increases in excess capacity, costs, and prices; $i$ ) by contrast, research based on more recent data generally finds that it contributes to a reduction in excess capacity, costs, and prices. There are some exceptions, of course, such as Manheim et al. (1994).

4. During 2001, the FTC placed renewed emphasis on stopping collusion and other anti-competitive practices that raise health care costs and decrease quality. In particular, given the strongly growing cost of prescription drugs, the FTC dramatically increased its attention to pharmaceutical-related matters, to which one-quarter of its resources were devoted in 2001. In its non-merger enforcement cases, the FTC focused on efforts by branded drug manufacturers to slow or stop competition from lower-cost generic drugs. With regard to health care providers, antitrust investigations put a stop to anti-competitive collusive conduct of several groups of physicians, which was found to have driven up consumer costs. 
Given declining demand for inpatient hospital services, potential gains from economies of scale and increased price sensitivity on the part of buyers, some degree of horizontal consolidation in health care markets may be appropriate. New technologies have led to less invasive medical interventions and more outpatient care, which has left many hospitals with costly excess capacity (Gaynor and Anderson, 1995). Using data from over 3500 hospitals in the years 1986-94, Conner et al. (1997) found that, on average, merging hospitals reduced costs more than others. However, the cost savings from mergers were significantly higher in less concentrated markets. Efficiency gains from economies of scale can be exhausted at relatively small sizes (Given, 1996). As to economies of scope, for example in the monitoring of health care services, it is not clear that companies must be large to achieve such efficiency gains, the more so since firms specialising in these services have sprung up.

There are only a few empirical studies that estimate the effects of consolidations on prices or health outcomes. Applying the methods in Kessler and McClellan (2000) to two hospital merger cases that faced FTC scrutiny during 1994-95, Kessler and McClellan (1999) confirm that both the proposed mergers would have lowered the degree of competition. But they find that, for Medicare patients with heart disease, only one merger would clearly have led to higher expenditures and increased rates of adverse health outcomes. The US antitrust authorities have lost several cases when evidence showed that a non-negligible fraction of patients travelled outside the community, so that merged hospitals would have lacked the monopoly power to raise prices significantly. Noting that a majority of patients are averse to travel, Capps et al. (2001) show that hospital mergers can lead to significant price increases. Some evidence also suggests that merged HMOs seem to increase premiums (Christianson et al., 1997). However, the overall causal relationship between HMO mergers and subsequent premium increases is rather weak. This is possibly due to the threat of potential entry of new competitors (i.e. market contestibility).

The tentative conclusion drawn from the evidence is that some degree of competition is advantageous, but that the various kinds of market failures point to the need for circumscribing its extent through appropriate regulation. This is by no means easy, because health care is a complex market and because it is so closely intertwined with the market for health insurance, itself heavily regulated. 


\section{RECENT ECONOMICS DEPARTMENT}

\section{WORKING PAPERS}

The full series of Economics Department Working Papers can be consulted at www.oecd.org/eco/Working Papers/

349. The Effectiveness of Public Expenditure in Portugal (February 2003) Chiara Bronchi

348. Comparative Analysis of Firm Demographics and Survival: Micro-Level Evidence for the OECD Countries (February 2003) Eric Bartelsman, Stefano Scarpetta and Fabiano Schivardi

347. Regulation, Productivity and Growth: OECD Evidence (January 2003) Giuseppe Nicoletti and Stefano Scarpetta

346. Public Expenditure Management in Poland (December 2002) Andrew Burns and Kwang-Yeol Yoo

345. Enchancing the Effectivesness of Public Expenditure in Sweden (December 2002) Deborah Roseveare

344. The Decline in Private Saving Rates in the 1990s in OECD Countries: How Much Can Be Explained by NonWealth Determinants (November 2002) Alain de Serres and Florian Pelgrin

343. Enhancing the Effectiveness of Public Expenditure in Norway (October 2002) Isabelle Joumard and Wim Suyker

342. Productivity and Convergence in a Panel of OECD Countries: Do Regulations and Institutions Matter? (September 2002) Stefano Scarpetta and Thierry Tressel

341. Managing Public Expenditure: The UK Approach (August 2002) Paul van den Noord

340. The Brazilian Pension System: Recent Reforms and Challenges Ahead (August 2002) Marcos Bonturi

339. Challenges in the Mexican Financial Sector (August 2002) Marcos Bonturi

338. Coping with Population Ageing in Hungary (August 2002) Andrew Burns and Jaromir Cekota

337. Next Steps for Public Spending in New Zealand: The Pursuit of Effectiveness (July 2002) Dave Rae

336. Strengthening the Management of Public Spending in Hungary (July 2002) Jaromir Cekota, Rauf Gonenc and Kwang-Yeol Yoo

335. Automatic Stabilisers and Market Flexibility in EMU: Is There a Trade-Off? (July 2002) Marco Buti, Carlos Martinez-Mongay, Khalid Sekkat and Paul van den Noord

334. The Economic Consequences of Terrorism (July 2002) Patrick Lenain, Marcos Bonturi and Vincent Koen

333. Investment in human capital through post-compulsory education and training: Selected efficiency and equity aspects

(July 2002) Sveinbjörn Blöndal, Simon Field and Nathalie Girouard

332. Enhancing the Effectiveness of Public Spending in Switzerland (June 2002) Isabelle Joumard and Claude Giorno 
331. Competition and Efficiency in Publicly Funded Services (June 2002) Jens Lundsgaard

330. Policy Pre-Commitment and Institutional Design: A Synthetic Indicator Applied to Currency Boards (May 2002) Marie-Thérèse Camilleri Gilson

329. The Role of Policy and Institutions for Productivity and Firm Dynamics: Evidence from Micro and Industry Data (April 2002) Stefano Scarpetta, Philip Hemmings, Thierry Tressel and Jaejoon Woo

328. Improving the Efficiency and Sustainability of Public Expenditure in the Czech Republic (April 2002) Andrew Burns and Kwang-Yeol Yoo

327. Increases in Business Investment Rates in OECD Countries in the 1990s: How much can be explained by fundamentals? (April 2002) Florian Pelgrin, Sebastian Schich and Alain de Serres

326. Sectoral Shifts in Europe and the United States: How They Affect Aggregate Labour Shares and the Properties of Wage Equations

(April 2002) Alain de Serres, Stefano Scarpetta and Christine de la Maisonneuve

325. Coping with Population Ageing in the Netherlands (March 2002) David Carey

324. Public Spending in Italy: Policies to Enhance its Effectiveness (March 2002) Alexandra Bibbee and Alessandro Goglio

323. Overheating in Small Euro Area Economies : Should Fiscal Policy React? (March 2002) Peter Hoeller, Claude Giorno and Christine de la Maisonneuve

322. Encouraging Environmentally Sustainable Growth in Austria (February 2002) Jens Høj and Andreas Wörgötter

321. Health Care Reform in Japan (February 2002) Yutaka Imai

320. Enhancing Expenditure Control with a Decentralised Public Sector in Denmark (February 2002) Steen Daugaard

319. Options for Reforming the Finnish Tax System (February 2002) Isabelle Joumard and Wim Suyker

318. Product Market Regulation and Wage Premia in Europe and North America: An Empirical Investigation (January 2002) Sébastien Jean and Giuseppe Nicoletti

317. Competition, Innovation and Productivity Growth: A Review of Theory and Evidence (January 2002) Sanghoon Ahn

316. Labour Market Institutions, Product Market Regulation, and Innovation : Cross Country Evidence (January 2002) Andrea Bassanini and Ekkehard Ernst

315. Ongoing Changes in the Business Cycle - Evidence and Causes (January 2002) Thomas Dalsgaard, Jorgen Elmeskov and Cyn-Young Park 